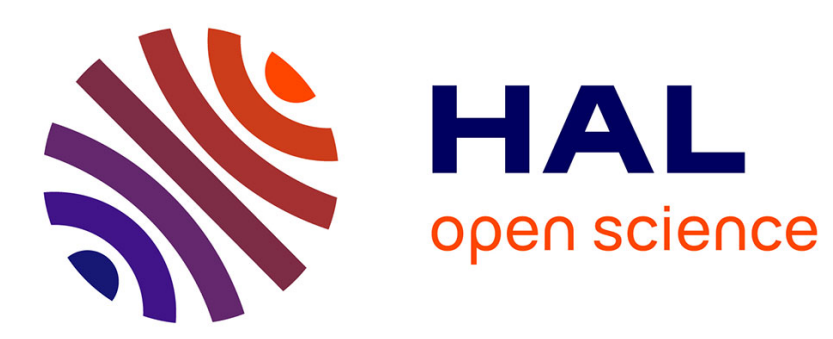

\title{
The Dynamics of Gasoline Prices: Evidence from Daily French Micro Data
}

Erwan Gautier, Ronan Le Saout

\section{To cite this version:}

Erwan Gautier, Ronan Le Saout. The Dynamics of Gasoline Prices: Evidence from Daily French Micro Data. 2012. hal-00759095

\section{HAL Id: hal-00759095 \\ https://hal.science/hal-00759095}

Preprint submitted on 30 Nov 2012

HAL is a multi-disciplinary open access archive for the deposit and dissemination of scientific research documents, whether they are published or not. The documents may come from teaching and research institutions in France or abroad, or from public or private research centers.
L'archive ouverte pluridisciplinaire HAL, est destinée au dépôt et à la diffusion de documents scientifiques de niveau recherche, publiés ou non, émanant des établissements d'enseignement et de recherche français ou étrangers, des laboratoires publics ou privés. 
EA 4272

\title{
The Dynamics of Gasoline Prices: Evidence from Daily French Micro Data
}

\author{
Erwan Gautier* \\ Ronan Le Saout**
}

$2012 / 41$

* University of Western Brittany (Brest) and Banque de France

${ }^{* *}$ Crest-ENSAE and Ecole Polytechnique Paris

Laboratoire d'Economie et de Management Nantes-Atlantique Université de Nantes

Chemin de la Censive du Tertre - BP 52231

44322 Nantes cedex 3 - France

www.univ-nantes.fr/iemn-iae/recherche

Tél. +33 (0)2 40141717 - Fax +33 (0)2 40141749 


\title{
The Dynamics of Gasoline Prices: \\ Evidence from Daily French Micro Data*
}

\author{
Erwan Gautier ${ }^{\dagger} \quad$ Ronan Le Saout ${ }^{\ddagger}$
}

18 September 2012

${ }^{*}$ We would like to thank Guillaume Retout and Laurent Baudry for their research assistance. We are grateful to Etienne Chamayou et Aurélien Violon for providing us some data on gas stations characteristics. We also thank Anindya Banerjee, Nicoletta Berardi, Gilbert Cette, Emmanuel Flachaire, Koen Jochmans, Hervé Le Bihan, Michel Lubrano, Aidan Meyler, Michel Normandin, and Patrick Sevestre as well as participants in the 2012 Royal Economic Society Conference (Cambridge, 2012), $29^{\text {th }}$ Journées de Microéconomie Appliquée (Brest, 2012), the $61^{\text {st }}$ AFSE Congress (Paris, 2012), the $16^{\text {th }}$ T2M Conference (Nantes, 2012), $18^{\text {th }}$ International Panel Data Conference (Paris, 2012) and seminars at Banque de France (Paris, 2011), CREST-LEI (Paris, 2011), GREQAM (Marseille, 2012), University of Nantes (2012) for helpful discussions and remarks. The project was initiated when R. Le Saout and E. Gautier were researchers at Banque de France. E Gautier would like to thank the "Chaire Finance" from the "Fondation de projets de l'Université de Nantes" for its financial support. This paper does not necessarily reflect the views of the Banque de France.

${ }^{\dagger}$ Corresponding author. University of Western Brittany (Brest) and Banque de France, 12 rue de Kergoat, CS 93827, 29238 BREST Cedex 3, France. Email adress: erwan.gautier@univ-brest.fr

${ }^{\ddagger}$ Crest-ENSAE and Ecole Polytechnique, Paris. Email adress: ronan.le-saout@ensae.fr 


\begin{abstract}
Using millions of individual gasoline prices collected at a daily frequency, we examine the speed at which market refined oil prices are transmitted to consumer liquid fuel prices. We find that on average gasoline prices are modified once a week and the distribution of price changes displays a M-shape as predicted by an adjustment cost model. Using a reduced form statedependent pricing model with time-varying random thresholds, we find that the degree of pass through of wholesale prices to retail gasoline prices is on average 0.77 for diesel and 0.67 for petrol. The duration for a shock to be fully transmitted into prices is about 10 days. There is no significant asymmetry in the transmission of wholesale price to retail prices.

Keywords: price stickiness, adjustment costs, $(\mathrm{S}, \mathrm{s})$ models, gasoline price.
\end{abstract}

JEL Codes: E31, D43, L11 


\section{Introduction}

At which speed agents incorporate specific or common shocks into their prices is a crucial issue in macroeconomic models. Why are prices sticky and fail to adjust immediately to their fundamentals? Using individual gasoline prices collecting at a daily frequency in more than 10,000 gas stations in France, we examine in this paper to which extent retail gasoline prices are rigid and how long it takes for a gas station to incorporate an oil price shock.

The first contribution of the paper is to investigate the degree of price rigidity of gasoline prices in France. For that purpose, we use a rich and unique data set of daily price quotes collected by the French Ministry for the Economy for diesel and unleaded petrol. Prices are collected in almost all retailers selling gas in France. The time dimension of the data set is also quite large: data are collected every day between January 2007 and June 2009. All in all, the data set consists of more than 8 million individual price quotes. We examine the basic patterns of price rigidity in French gas stations and the main findings are the following: (i) prices are modified on average once a week ${ }^{1}$; (ii) there is some heterogeneity between firms: supermarkets change their prices more often than other gas stations; (iii) prices are more likely to be modified on Tuesday and Friday than between Saturday and Monday; (iv) price decreases are as frequent as price increases; (v) the average price change in absolute values is around 2.5\%; (vi) small price changes are rather scarce.

Our paper also contributes to the empirical literature on price rigidity models. One key issue is to understand why prices remain constant during a certain period of time though the price of oil fluctuates every day: how can we rationalize that prices are on average modified only once a week? Different theoretical models are used in macroeconomics to rationalize the infrequent changes of prices. Several papers have recently examined patterns of micro prices to assess the relevance of the different models. ${ }^{2}$ However, at the micro level, one difficulty is

\footnotetext{
${ }^{1}$ By comparison, using respectively US and French monthly consumer price data, Bils and Klenow (2005) and Dhyne et al. (2011) obtain average price durations for energy products about $0.6-0.7$ month. Using daily wholesale micro prices for the United States, Hamilton and Davis (2004) and Douglas and Herrera (2010) find that prices are modified every three days on average. Davis (2007) obtains that the frequency of price changes is about $10 \%$ on average using daily data collected in 4 gasoline retailers in the United States.

${ }^{2}$ See for instance Nakamura and Steinsson (2008) or Klenow and Kryvtsov (2008) for the United States or
} 
to observe firm-level determinants of pricing behaviour and sectoral inflation is often used to identify aggregate shocks on micro prices (see for example Fougere et al. $(2007)^{3}$ ). In our study, we use daily prices of diesel and unleaded petrol set at the Rotterdam market to approximate the marginal cost of diesel and unleaded petrol retail prices. We estimate a reduced form of a time-varying adjustment cost model that links prices to costs. The probability of price changes depends on the gap between the nominal price and the price that would be observed without friction. If this gap exceeds a certain threshold, prices are adjusted; the threshold trigerring price changes is assumed to depend positively of the adjustment cost. We also suppose that the adjustment cost is random over time and depends on the day of the week. Using wholesale gasoline price data, Davis and Hamilton (2004) estimate a fixed menu cost model. However, this model can replicate only partially what we observe in the data. In particular, a fixed menu cost model predicts that the size of price changes is constant over time for a given firm. Our time-varying adjustment cost model allows us to predict some heterogeneity in the size of price changes over time for a given firm (Gautier and Le Bihan, 2011). Moreover, our model represents simultaneously the decision of price change but also the size of the price change if there is a price change. Compared to Davis and Hamilton (2004), we use information on the size of price change which helps us to identify determinants of the fundamentals underlying gasoline prices. In particular, we are able to estimate the degree of pass-through of Rotterdam prices to gasoline prices. Finally, we estimate our model for 8,000 firms which allows us to provide a distribution of parameters. We find that the time-varying adjustment cost model helps to predict the $M$-shape of the price change distribution. Several results are obtained from those estimations: (i) the degree of pass-through of wholesale prices to retail prices is on average 0.77 for diesel and 0.67 for unleaded petrol; (ii) this pass-through is larger in supermarkets than in other gas stations; (iii) adjustment thresholds are quite large but show also a large variability.

Our last contribution is to examine how long it takes for gas stations to incorporate a shock on wholesale prices to their retail prices and whether this response is symmetric. For that, we use Dhyne et al. (2006) or Vermeulen et al. (2012) for the euro area.

${ }^{3}$ Ratfai (2006) used wholesale price of meat to capture the marginal cost of meat retail prices and Fougere et al. (2010) approximated the labour cost of restaurants by using the national minimum wage. Dhyne et al. (2011) estimate an unobserved synthetic factor to identify price fundamentals. 
simulated trajectories of our microeconometric model and study the aggregation of non-linear pricing strategies followed by heterogenous firms. We find that the aggregate price adjustment is rather quick: on average, it takes around 10 days for a shock to be fully transmitted into retail gasoline prices. Using aggregate data collected either at a monthly or weekly frequency, a large empirical literature deals with the (a)symmetric transmission of shocks into gasoline prices. Results are quite contrasted depending on the methodology or data used but asymmetry is not pervasive (Frey and Manera, 2007). ${ }^{4}$ Using parameter estimates of our microeconometric model, we first test the presence of asymmetries in the probability of price changes. More specifically, we test whether the threshold triggering price increases is lower than the threshold triggering price decreases. We find no significant asymmetry. Those results are confirmed when we study the aggregate response of our simulated trajectories to different shocks. Finally, we compare the aggregate responses of prices obtained when we assume different models of price rigidity (Calvo, fixed $(S, s)$ model or variable $(S, s)$ model). We find that the longest delay is obtained for the Calvo model where it takes more than two weeks for a shock to be fully transmitted. ${ }^{5}$

The layout of the paper is as follows. Section 2 describes the data set we use in this study and the main features of the gasoline retail market in France. In section 3, we provide the main stylised facts on gasoline price rigidity. Section 4 presents the price rigidity model we estimate. Our main results are presented in Section 5. We also test the presence of asymmetry and the fit of the model to the data. In section 6 , we estimate the delay for retail prices to respond to aggregate shocks and examine how prices are adjusted after the shock depending on the price rigidity model. Section 6 concludes.

\section{Daily Micro Data on Gasoline Prices}

In this section, we describe the micro data set of gasoline prices we use. This data set consists of individual prices reported by all gas stations selling more than $500 \mathrm{~m}^{3}$ of gasoline per year

\footnotetext{
${ }^{4}$ For France, Audenis et al. (2002), using macro monthly time series find no asymmetry at the retail level but a significant asymmetry at the refinery level.

${ }^{5}$ By comparison, Audenis et al. (2002) find a duration around 3 months whereas in a recent macro contribution Meyler (2009) obtains a 4-week duration for a shock to be incorporated into gasoline prices.
} 
in France. Since January 2007, gas stations have to report all their price changes for unleaded petrol and diesel to the Ministry of Economy. The data collected are then made available on a governmental web site (http://www.prix-carburants.gouv.fr). This web site is intended to foster competition by providing a public and free information on prices. Some other private web sites offer similar services but the updating of prices is only voluntary whereas in our case, the public administration may force retailers to report their price changes. ${ }^{6}$ The main variables available in our data set are the following. First, the price of a liter of diesel and unleaded petrol; this price includes all taxes, expressed in euros with three decimals. Another variable is the date of the report expressed in $\mathrm{DD} / \mathrm{MM} / \mathrm{YY}$, which enables us to follow the same price in a given retailer. An identification number is associated to each retailer. We have some information on the retailer: brand name, location and services offered in the gas stations. We use historical data extracted every day at 23:59 from this governmental web site for the period from January 1st 2007 to May 31th 2009. All in all, our price data contains more than 10,000 gas stations and about 8 million price quotes for diesel and unleaded petrol which are the main types of liquid fuels consumed in France. ${ }^{7}$

The French market of gasoline consists of four types of retailers: (i) gas stations belonging to supermarkets; (ii) gas stations belonging to major oil companies like Total, Elf, Shell...; (iii) small independent retailers which do not depend from major oil companies; (iv) gas stations located on motorways which often belong to oil companies. One important feature is that the level of prices is on average lower in supermarkets than in other gas stations. Supermarket gas stations represent about $60 \%$ of the total market share whereas only $40 \%$ of gas stations belong to supermarkets. Our data set includes about 4,500 stations associated with supermarkets and about 5, 500 stations for other gas stations.

The retail gasoline price can be decomposed in three main elements: (i) the wholesale price

\footnotetext{
${ }^{6}$ The French competition authority is in charge of the website and the accuracy of information. For instance, between January 2011 and June 2011 about 6,000 gas stations were controlled and 72 notices of violation were issued by inspectors. Moreover, 600,000 consumers visit regularly the website and can declare (via mail and phone) if the price is different on the website.

${ }^{7}$ In France, the consumption of diesel is about three times higher than the consumption of unleaded petrol whereas about $40 \%$ of unleaded petrol production is exported and $40 \%$ of diesel consumption is imported.
} 
of fuel (after refining) about $75 \%$ to $85 \%$ of total operating expenses of the gas stations. ${ }^{8}$ In this study, we approximate this cost by using the price of refined fuels quoted in Rotterdam. ${ }^{9}$ We consider this wholesale price because it includes refining costs contrary to Brent prices for example; (ii) distribution costs include labor and transportation costs. They are not observed per se in our study, those costs might not change at a daily frequency and may depend on each gas stations, they will be considered as idiosyncratic; (iii) taxes. In 2009, the two main taxes (VAT and TIPP) represented $65 \%$ of the unleaded petrol prices and $60 \%$ of diesel prices. The TIPP (domestic excise tax on petroleum products) depends on the volumes and not on the selling price of the product; it can be revised in January each year but remains fixed from 2007 to 2009 . The VAT rate is $19.6 \%$ and is calculated on the price including the TIPP. The VAT rate was not modified during our sample period. We use prices excluding all taxes according the following formula: $p_{\text {excl_taxes }}=\frac{p_{\text {inclu_taxes }}}{1+V A T}-T I P P$ where $p_{\text {excl_taxes }}$ is the price excluding taxes, $p_{\text {inclu_taxes }}$ the price including all taxes, $V A T$ the VAT rate and TIPP the TIPP excise. Gasoline prices are usually displayed with three decimal places in gas stations and prices are collected and reported by the Ministry of Economy with three digits. The posting of two or three digits is a choice made by gas stations and not a technical constraint. So prices with three decimal places will be considered in the following sections.

Data are corrected for some measurement errors. Occurrences of price increases followed by decreases equivalent next day and breaks in the series have been identified and corrected. These adjustments affect about $1 \%$ of gas stations in our microdata set and few dates. The initial micro data set includes very long prices durations, we consider that price durations longer than one month are outliers, which represent less than $2 \%$ of price trajectories. These outliers can be explained by the learning process of the price collection and the absence of obligation of reporting for very small gas stations. We also drop observations with a majority of price trajectories longer than one month, and gas stations whose prices are observed during a period of less than 3 months. After treatment of outliers and measurement issues, our sample contains

\footnotetext{
${ }^{8}$ Figures are computed using sectoral national accounts published by Insee.

${ }^{9}$ As noted by Meyler (2010), Rotterdam is one of the three major trading areas for refined products (168 million tonnes). However, some Mediterranean ports handle also smaller amounts of liquid petroleum products (Marseilles (66 million tons) and Trieste (36 million tons)).
} 
about 7 million of price quotes for each type of liquid fuel and 10, 000 gas stations.

We have no information on the demand addressed to each individual gas station (like the number of liters sold) or on the quality of the product. However, we can consider that the product is rather homogenous in terms of quality. Our data set is not exhaustive in terms of gas stations because there is a threshold requirement for participation. It still includes a significant number of gas stations. We test the consistency of our indication coming from individual data set by confronting our data to other sources. The French Ministry of the Economy publishes every week the aggregate weighted average price of unleaded petrol and diesel (with and without taxes) sold in France. Figure A in Appendix compares the simple average of prices from our data set and macro price series published by the Ministry of Economy. The correlation coefficient is close to 0.99 . The difference for prices excluding taxes is on average 0.009 euros for diesel and 0.016 for unleaded petrol. One possible explanation is that prices in supermarkets are lower and may be underrepresented by a simple average. Finally, we observe a rather close comovement between market prices of Rotterdam and retail gasoline prices.

\section{Stylized Facts on Gasoline Price Rigidity}

In this section, we describe the main patterns of price setting behaviour of French gas stations using basic indicators of price rigidity.

\subsection{Frequency of price changes and price durations}

The frequency of price changes or the duration between two price changes are often considered as good indicators of price rigidity. The longer a price lasts, the more rigid this price is considered to be. Gasoline prices are known to be among the less rigid prices. Table 1 summarizes our results on the frequency of price changes and on price durations. We find that on average diesel prices are modified every 5 days if we consider all individual price quotes together and every 6.5 days if we consider the distribution of average firm-level durations. The average duration of unleaded petrol prices are a little longer ( 7 days). The average frequency of price changes is $16.5 \%$ for unleaded petrol and $17.6 \%$ for diesel prices. Those figures are difficult to compare 
with monthly frequency data since all gasoline prices collected at a monthly frequency would imply a $100 \%$ frequency of price changes. Using daily US data of wholesale prices, Davis and Hamilton (2004) and Douglas and Herrera (2010) obtain price durations shorter than one week.

Figure 1 plots the distribution of average firm-level price durations for diesel and unleaded petrol prices. We find some heterogeneity among firms on price durations. $25 \%$ of gas stations change their prices on average every 8 days or more whereas another quarter of firms change their prices every 5 days or less. On average supermarkets modify more frequently their prices than other gas stations which often belong to oil companies (6 days in supermarkets versus 7 days in other gas stations).

Figure 2 plots the hazard rate of price durations for diesel and unleaded petrol prices. The hazard rates are rather flat but there are some significant peaks at durations 7, 14 and 21 days and to a lesser extent at durations 3 and 4 days. This finding implies some strong regularities in the day of price changes. Firms prefer changing their price once a week at the same day. Table 2 summarizes results on proportions of price changes over days of the week. About $40 \%$ of price changes occur on Tuesday and Friday whereas price changes are less frequent on Monday, Saturday and Sunday. ${ }^{10}$ Such regular patterns over the week are not observed in Rotterdam wholesale prices and may be the consequence of differences in price adjustment costs over the week. Zbaracki et al. (2004) and Muller et al. (2010) both mention that adjusting prices involve a rather long process because managers have to collect information on costs or on prices from competitors. The timing of price adjustment would be modified by this process of collecting information and would not be driven only by changes in wholesale Rotterdam prices.

\subsection{The distribution of price changes}

On the size of price changes, we obtain that price increases are almost as frequent as price decreases. The frequency of diesel price increases is on average $8.7 \%$ versus $8.9 \%$ for price decreases whereas for unleaded petrol prices the frequency of price increases is $8.7 \%$ versus $7.8 \%$

\footnotetext{
${ }^{10}$ Similar evidence is also reported by Asplund et al. (2000) on Swedish gasoline prices. Many gas stations are open on Sunday and consumers can use automatic pumps and payments by credit cards. However, it is more doubtful that an employee is present to change prices or even to decide to change prices.
} 
for price decreases (Table 1). If shocks are equally distributed between increases and decreases, this might suggest no asymmetry in price changes for diesel and a rather small one for unleaded petrol.

Table 3 summarizes the main statistics on the size of price changes. For diesel and unleaded petrol, the average price increase (resp. $2.3 \%$ and $2.9 \%$ ) is close to the average price decrease (resp. $-2.4 \%$ and $-2.9 \%$ ) in absolute values. Price changes are larger for supermarkets than for other gas stations. The average price change in supermarkets is about $2.5 \%$ for diesel and $3.1 \%$ for unleaded petrol whereas it is respectively $2.2-2.3 \%$ and $2.6-2.7 \%$ for other gas stations (Table 3). Figure 3 plots the distributions of price changes different from 0 . One original pattern of those distributions is their $M$-shape. ${ }^{11}$ Small price changes (in percentage) are rare. ${ }^{12}$ Less than $25 \%$ of price changes are smaller than half the median of price changes whereas for instance whereas Klenow and Kryvtsov (2008) find a proportion close to $40 \%$ on US CPI data. This $M$-shape of the distribution of price changes is consistent with a distribution of price changes predicted by a standard menu-cost model. This small proportion of small price changes could also be due to frequent large changes in production costs. However, the distribution of market price changes is close to a normal distribution with zero mean. Another explanation might be related to the number of digits used to display prices. In a large majority of outlets, prices are displayed with three digits after the comma. So, in principle price changes could be smaller than $1 \%$. For example, if the diesel price (excluding taxes) is 0.451 euros (i.e. close to the minimum price on our sample period), the retailer can decide to increase its price by 0.001 euros and the price increase in percentage would be $0.22 \%$. However, the distribution of the last digit in prices (including all taxes) is not uniform: $31 \%$ of gasoline prices end with "9", $29 \%$ with "0", $9 \%$ with "5", $7 \%$ with "4" whereas for other last digit figures this proportion is smaller than $5 \%$ (see Table $\mathrm{A}$ in appendix for details) whereas the distribution of the penultimate digit appears uniform (Knotek 2010 and Levy et al. 2011 provide similar evidence on other products). The timing of price changes might be modified by the presence of pricing points: firms wait for large

\footnotetext{
${ }^{11}$ Recently, using a test of unimodality, Cavallo and Rigobon (2011) find evidence in favor of bimodality in distributions of price changes in supermarkets.

${ }^{12}$ Asplund et al. (2000) using Swedish daily gasoline prices find such a distribution for price changes: there is no price changes less than $2 \%$.
} 
movements of wholesale prices before changing their prices because they want to increase or decrease their prices by 0.10 or 0.05 euros. Price durations for price points are longer (see Table A in Appendix) and small price changes would be less frequent. ${ }^{13}$

\section{Gasoline price rigidity: an empirical model}

Price changes in gas stations are infrequent whereas marginal costs are modified every day, price changes are on average rather large and small price changes are rare. Gasoline prices appear as a textbook example to illustrate price stickiness models. However, one key issue in most empirical studies on price rigidity is to measure at the firm level the determinants of prices. In price rigidity models, firms set their prices in a monopolistic competition framework. The price level that would be observed in the absence of rigidity called the frictionless prices is given by a mark-up over marginal costs. One difficulty is to measure at the firm level the marginal costs. Some empirical studies suppose that prices depend on aggregate inflation (Cecchetti 1986 or Fougere et al. 2007 for example). Other studies use better approximations at the aggregate level like wage costs or wholesale prices (see Fougere et al. 2010, Ratfai 2006 or Dutta et al. 2002). In a recent contribution, Dhyne et al. (2011) using a statistical decomposition, identify the marginal cost to an unobserved factor specific to the product. In our case, the marginal cost of gasoline prices is the wholesale prices of gasoline (diesel and unleaded petrol) quoted at the Rotterdam market.

We here estimate a rather flexible form of state-dependent model. This model aims at reproducing the main characteristics of gasoline price adjustments: i) price changes are infrequent; ii) the timing of price changes depends on the evolution of wholesale prices but also on the days of the week; iii) small price changes are quite rare but price changes vary a lot over time for a given firm. A standard adjustment cost model would predict that price adjustments are discrete, quite large and depend only on price fundamentals (here the price of Rotterdam refined oil products). In that model, there is a cost to adjust prices and firms trade off between the opportunity cost

\footnotetext{
${ }^{13}$ If we restrict our sample to prices not ending in "9", "0", or " 5 ", we still find that the distribution of price changes exhibit an M-shape (but less pronounced than for prices ending in "9", "0", and "5").
} 
of deviating from the optimal price (i.e. the foregone profit) and the adjustment cost. Firms tolerate that their actual posted price deviates from the frictionless price (i.e. the price that would have been observed without adjustment cost) as long as this deviation is not too large. ${ }^{14}$ The optimal frictionless price would be defined as:

$$
p_{i t}^{*}=\alpha_{i}+\beta_{i} p_{t}^{o}+\varepsilon_{1, i t}
$$

where $p_{i t}^{*}$ is the logarithm of the optimal price in the gas station $i$ at date $t$ and $p_{t}^{o}$ the logarithm of the price of refined oil product sold in Rotterdam at the spot market at day $t . \varepsilon_{1, i t}$ is a firm- and time-specific shock. We could interpret $p_{t}^{o}$ as a common shock to the frictionless price and $\varepsilon_{1, i t}$ as a specific or idiosyncratic shock to the frictionless price. Under some conditions shown to be of the $(S, s)$ type $^{15}$, the optimal adjustment rule is then to adjust the price only if the difference between the optimal price $p_{i t}^{*}$ and the price $p_{i t-\tau}$ modified at period $t-\tau$ (where $\tau$ is the duration since the last price change), exceeds some threshold $S_{i}$ (for price decreases) or $s_{i}$ (for price increases). When prices are reset, new prices are set at the optimal frictionless price. The firm's pricing decision depends on the distance covered by $p_{i t}^{*}$ between dates $t-\tau$ and $t$ (the date at which the decision is taken).

However, the $(S, s)$ model puts strong restrictions on the patterns of price adjustments. First, the size of the price change is the same for all price decreases $\left(S_{i}\right.$ in absolute values) and all price increases $\left(-s_{i}\right.$ in absolute values). This prediction is not consistent with the variance of price changes over time (for a given firm). Second,in a standard $(S, s)$ model, the timing of the price adjustment only depends on the frictionless price which is not completely consistent with our observations. We will rely here on a time-varying thresholds model. As shown by Caballero and Engel (1999) in a model of investment decision, thresholds that fluctuate over time can be obtained under such the assumption of a random menu cost. Dotsey et al. (1999) assume such random adjustment costs for prices. Woodford (2009) also show that predictions of information cost model could also be reproduced by a generalized $(S, s)$ model. In our model, to reproduce

\footnotetext{
${ }^{14}$ Another possible margin of adjustment for gas stations would be inventories. However, according to the French competition authority, at the retail level, inventory capacities are small and firms most often use a replacement value to set their prices. Our frictionless price can be considered as a replacement cost.

${ }^{15}$ See Seshsinki and Weiss (1977) or Hansen (1999).
} 
the timing and the size of price changes, the thresholds are allowed to vary over time and across firms. Overall, our approach is related to the adjustment hazard model developed by Caballero and Engel (1999): the probability of a price change is a function of the gap between the current price and a frictionless optimal price ${ }^{16}$ (see Figure B in appendix).

The price decision rule could summarized as follows:

$$
\begin{aligned}
\text { if } p_{i, t-\tau}-p_{i, t}^{*} \geq S_{i t} & p_{i t}=p_{i, t}^{*} \\
\text { if } p_{i, t-\tau}-p_{i, t}^{*} \leq s_{i t} & p_{i t}=p_{i, t}^{*} \\
\text { if } S_{i t}>p_{i, t-\tau}-p_{i, t}^{*}>s_{i t} & p_{i t}=p_{i t-\tau}
\end{aligned}
$$

where upper and lower bands are defined as:

$$
\begin{aligned}
S_{i t} & =\gamma_{i S} X_{i t}-\varepsilon_{2, i t} \\
s_{i t} & =\gamma_{i s} X_{i t}+\varepsilon_{2, i t}
\end{aligned}
$$

where $S_{i t}$ and $s_{i t}$ are the upper and the lower stochastic bands, $X_{i t}$ are exogenous variables that modify the timing of price adjustments (here the days of the week) and $\varepsilon_{2, i t}$ is firm- and time-specific shock to the timing of price adjustment. The exogenous shock on the timing of adjustment is assumed to be independent from the shock $\varepsilon_{1, i t}$ on the optimal price. The adjustment hazard model is rather flexible. For instance, our model encompasses the Calvo model: when the threshold varies a lot (the variance of $\varepsilon_{2, i t}$ is very large), the model predicts a constant probability for a price change and can generate small price changes. If the threshold does not vary at all, the empirical model would reproduce the predictions of a standard fixed adjustment cost model (see also Dhyne et al. (2011), Fougere et al. (2010) and Gautier and Le Bihan (2011)).

This specification is close to the model considered in Davis and Hamilton (2004) or Douglas and Herrera (2010). However, we depart from those studies in one dimension. Those studies examining gasoline price rigidity focus on the probability of price change and estimate binary response or durations models but they do not consider information on the size of price adjustments. Following Dhyne et al. (2011) and Fougere et al. (2010) we here use the size of price

\footnotetext{
${ }^{16}$ That gap is the relevant state variable, so that despite the fact that an optimization problem underlies the decision rule, no expectation term is explicitly present.
} 
changes to identify first the idiosyncratic shock on the frictionless price (which might play a key role in predicting some specific features of price rigidity patterns) and second to disentangle the volatility of the frictionless price and the volatility of the adjustment cost over time.

The time dimension of our sample is quite large since we observe each gas station during more than 800 days. So, we estimate a pricing decision rule for every single gas stations and we are able to estimate the distributions in the gas station population of $\alpha, \beta, \sigma_{1}, \gamma_{s}, \gamma_{S}$ and $\sigma_{2}$. Then, we assess the degree of heterogeneity in the pass-through of oil prices to retail prices and in the adjustment costs over time and among firms.

An asymmetry in price changes is introduced by allowing asymmetric adjustment thresholds: a lower absolute value of $s$ compared to $S$ would imply a quicker adjustment to wholesale price increases than to wholesale price decreases. This possible asymmetry in the thresholds trigerring price changes is introduced to mimic possible asymmetries in adjustment costs. We here extend Dhyne et al. (2011) by allowing $S$ and $s$ to be not necessarily equal in absolute values. However, in the long term, all firms will incorporate the wholesale price variations in their prices and the degree of pass-through is equal to $\beta .{ }^{17}$

In our econometric specification there are two main stochastic processes and two groups of parameters to estimate: the first process is the one associated to the frictionless price, we estimate for each gas station $i, \alpha, \beta$ and $\sigma_{1}\left(\varepsilon_{1, i t}\right.$ are supposed normally distributed with mean 0 and variance $\sigma_{1 i}^{2}$ ). The second group of parameters is associated to the time-varying adjustment thresholds where we estimate $\gamma_{S}, \gamma_{s}$ and $\sigma_{2}\left(\varepsilon_{2, i t}\right.$ are supposed normally distributed with mean 0 and variance $\sigma_{2 i}^{2}$ ). Formally, our model is a bivariate sample selection model where the first equation gives the price change decision and the other one the size of the price changes. If the same regressors appear in both equations, the identification comes from the functional form (Wooldridge 2002). We here use an exclusion restriction, following Fougere et al (2010) we assume that the adjustment thresholds vary with the day of the week. The frequency of price changes varies significantly over the week whereas the average size of price changes is rather constant over the days of the week. Those differences could be explained by two causes: first,

\footnotetext{
${ }^{17}$ For simplicity, we assume that the idiosyncratic shock associated to thresholds $\varepsilon_{2, i t}$ is similar when prices decrease or increase.
} 
some gas stations may be closed during the weekend or at least there is no employee to physically change prices; second, this seasonality could reflect the process of information acquisition (as described for instance in Asplund et al. (2000)). Gas companies observe oil prices on Monday and decide at a more or less centralized level to change their prices on Tuesday conditionally on changes in oil prices at the beginning of the week. Then price change decisions should be communicated to all gas stations and it could be costly and rather long. ${ }^{18}$ This seasonality would affect the timing of price adjustment but not the frictionless price which is mainly governed by wholesale prices. ${ }^{19}$

We estimate this model using standard maximum likelihood function procedures. An Appendix provides details of calculations for the likelihood function. This model is estimated separately for diesel and unleaded petrol. We restrict our sample to all firms observed more than one year in order to have a sufficiently large time dimension. For diesel prices, the sample contains 7,917 gas stations and for unleaded petrol prices, it contains 7, 211 gas stations. We also exclude observations made on Sundays since there are very few price changes on Sundays and identification of thresholds associated to Sunday observations is difficult.

\section{Results}

Table 4 reports estimation results of the time-varying $(S, s)$ models separately for diesel and unleaded petrol prices. We report statistics on the distribution of parameters estimated firm by firm.

\subsection{Frictionless price}

The first three lines of the Table 4 report results associated with the frictionless price $p^{*}$. The pass-through of the wholesale market price (Rotterdam prices) to retail prices is always positive and significant in all firms but it is different from 1. For diesel prices, the average pass-through

\footnotetext{
${ }^{18}$ See Muller et al. (2010) or Zbaracki et al. (2004) for additional evidence.

${ }^{19}$ Woodford (2009) and Alvarez et al. (2011) propose theoretical models where firms have to face a cost of information and a menu cost and they show that their models are able to match most of empirical features of price data.
} 
of French gas stations is 0.77 and its median is 0.80 whereas for unleaded petrol prices this passthrough is somewhat lower close to 0.67 on average and to 0.68 for the median. This parameter captures in our model the weight of wholesale gasoline in the firm cost function. Using national accounts in the retail gasoline sector, the share of wholesale gasoline cost in total costs is about 75 to $85 \%$ which is quite consistent with our results.

Figure 4 displays the whole distribution of $\beta$ parameters estimated using gas station data. For both diesel and unleaded petrol prices, we find that the distributions of the $\beta$ coefficients have two different modes. This heterogeneity corresponds to differences in the degree of passthrough between supermarkets and other gas stations. We find that for diesel prices, the average pass-through is 0.81 in supermarkets and 0.73 in other gas stations (Table 5). The variability in the degree of pass-through is lower for supermarkets than for other gas stations (the standard deviation of $\beta$ estimates is respectively 0.04 and 0.07 ). For unleaded petrol prices, we obtain similar conclusions, the pass-through is a little higher in supermarkets than in other gas stations (0.70 versus 0.64$)$ but the difference is smaller. To examine more deeply the heterogeneity of $\beta_{i}$, we run additional regressions where we explain differences between the determinants of $\beta$ by local competition variables, firm-level and local population characteristics. Tables 6 and 7 present the results of those OLS regressions. First, we find that local competition variables play a significant role. In particular, the distance of a given gas station to the closest supermarket has a negative effect on $\beta_{i}$ whereas the density of supermarkets tend to increase $\beta_{i}$ for both diesel and unleaded petrol. Supermarkets are more likely to charge lower prices and respond more quickly to cost changes, so they increase the competition pressure on other gas stations. The degree of pass through of gasoline stations on motorways is lower on average. Here again, gas stations on motorways are quite scarce and the degree of competition is lower. We also find that gas stations using pricing points strategies ${ }^{20}$ tend to have significant lower $\beta_{i}$. Moreover, local economic variables appear significant. Gas stations located in urban areas (except Paris and its suburbs) show larger pass-through coefficients than in rural areas. Another indicator of density is the share of households owning at least one car, this variable has a positive effect on $\beta_{i}$. The unemployment rate tends to increase $\beta_{i}$. Finally, services offered in gas stations have a

\footnotetext{
${ }^{20}$ We use a dummy variable equal to one if $95 \%$ or more of prices in a gas station end with a "0" or a "9".
} 
mixed impact on the pass-through.

The parameter $\alpha_{i}$ is supposed to capture the average firm's mark-up. We find rather small values for this parameter: about $2 \%$ on average for diesel and around $-2 \%$ for unleaded petrol. Since we do not observe all costs at the gas-station-level, the parameter $\alpha$ will also capture the effect of other costs on the frictionless price, which reduces the estimated mark-ups. ${ }^{21}$ We can assume that other costs such as labour costs are not modified at a daily frequency and did not move significantly during our sample period. So, the parameter $\alpha_{i}$ do not provide an exact estimation of the mark-up level but is correlated with mark-ups. We interpret heterogeneity in $\alpha_{i}$ among gas stations as differences in mark-ups. ${ }^{22}$ For instance, we find large differences in $\alpha_{i}$ between supermarkets and other gas stations: mark-ups are lower in supermarkets than in other gas stations for both diesel and unleaded petrol (Table 5). Tables 6 and 7 show further results on the heterogeneity of mark-ups among gas stations. We find that the degree of competition has a negative significant effect on $\alpha_{i}$; in particular, when the distance to the closest supermarket is large, $\alpha_{i}$ is higher for both diesel and unleaded petrol. ${ }^{23}$ We also find that the local unemployment rate have a negative effect on $\alpha_{i}$. Those effects are rather consistent with Hosken et al. (2008) who find that the local population income has a positive impact on margins. Finally, when a gas station has a store and sells a high quality gasoline, the mark-ups are larger.

Finally, the estimated values of parameters $\sigma_{1}$ (Table 4) are on average quite large: $1.58 \%$ for diesel prices and $1.92 \%$ for unleaded petrol prices. We can interpret the impact of the market Rotterdam price as a common aggregate shock and $\varepsilon_{1}$ captures all firm and time-specific shocks. The large values of $\sigma_{1}$ reflects the importance of idiosyncratic shocks in triggering price changes;

\footnotetext{
${ }^{21}$ For instance, if we suppose a Cobb Douglas cost function, we would have, in logs : $m c=\beta p^{o}+(1-\beta) w$ where $m c$ the marginal cost of producing one liter of gasoline, $\beta$ the share of wholesale gasoline in the cost functon, $p^{o}$ the price of a liter of wholesale price and $w$ is price of other costs. The markup should be: $p-m c=$ $p-\beta p^{o}-(1-\beta) w=\alpha$. Since we do not observe $w$, we estimate $\widetilde{\alpha}=p-\beta p^{o}$ and it implies that $\widetilde{\alpha}<\alpha$ (if $W$ is less than 1 euro).

${ }^{22}$ To control for possible differences among gas stations in "other costs", we add controls for brand characteristics and local economic conditions.

${ }^{23}$ Hosken et al. (2008) find similar evidence but they do not find that competition indicators have a significant effect on stations' margins.
} 
this feature was acknowledged by many studies of the recent literature on price rigidity (e.g. Golosov and Lucas, 2007), it can explain why we observe relative large price changes (compare to the aggregate fundamentals) and why we can observe the same day price increases and decreases.

\subsection{Thresholds}

The second part of Tables 4 and 5 reports the parameters associated with the adjustment thresholds.

In a standard constant adjustment threshold model, large values of the bands reflect large costs of price changes and all price changes are equal to the size of the inaction band. In our framework, adjustment thresholds are time-varying, allowing for variability in the size of price changes over time for a given gas station. However, as shown by Gautier and Le Bihan (2011), in that case, the mapping between those parameters and the adjustment cost is not trivial: the mean and the variance of the threshold are positively related to fit the data. In particular, when both the mean and the variance of adjustment thresholds are large, the price setting behaviour is very close to a Calvo price setting model. We compare our results obtained with a time-varying $(S, s)$ model with results obtained from a standard $(S, s)$ model and a Calvo model (see Tables B and C in Appendix). First, as expected, the estimated adjustment thresholds in time-varying $(S, s)$ models are larger than those obtained for a fixed menu cost model. On average, for diesel prices the time-varying adjustment thresholds are larger than $4.33 \%$ in absolute values whereas the average size of price changes is less than $2.5 \%$. For unleaded petrol prices, the adjustment thresholds are a little larger more than $5.5 \%$ whereas the average price change in absolute values is around $3 \%$.

Second, the variation over the week of the thresholds reflects variations in the price adjustment cost. The thresholds are larger on Monday and Saturday (the median value is larger than $5 \%$ for price decreases and price increases on Monday and Saturday for diesel prices and around $7 \%$ for unleaded petrol prices), the thresholds are on average lower on Tuesday and Friday (about $4 \%$ for diesel prices and $5 \%$ for unleaded petrol prices). This result is consistent with the variations in the frequency of price changes over the week (see above). Mean and variance of adjustment thresholds are a little larger for supermarkets than for other gas stations, this 
result suggests that if the pass-through is larger for supermarkets, the decision of price change is less impacted by aggregate shocks. To examine in details the heterogeneity of thresholds among gas stations, we present in Tables 6 and 7 OLS regressions of estimated band width (average of $S$ and $s$ ) on competition, firms' characteristics and local variables. We find that the degree of competition has a significant negative impact on the thresholds: for instance, the number of supermarkets close to a gas station tends to lower the band of inaction. We also find that pricing points strategies have a strong significant impact on thresholds. Firms that use only attractive prices (ending in 0 or 9 ) are likely to have larger adjustment cost and show larger inaction bands. Moreover, thresholds are significantly lower in urban areas than in rural areas whereas services offered in gas stations play a mixed role on inaction bands.

Finally, the mean variability of the shock $\varepsilon_{2}$ associated with the adjustment threshold is quite large about $3.1 \%$ for diesel prices and $4.1 \%$ for unleaded petrol prices (Table 4). This explains the gap between the average observed price change and the average estimated adjustment threshold (see Gautier and Le Bihan 2011 for details). A high value of this parameter helps to replicate the large variability in the size of price changes for a given station.

To test the presence of asymmetry in the response of gasoline prices to shocks on the wholesale price, we use the estimates obtained for the adjustment thresholds. If there is some downward price rigidity, it would imply that on average, for a given absolute value of the price gap $\mid p_{i, t-\tau}-$ $p_{i, t}^{*} \mid$, a firm would be more likely to hit the threshold trigerring price increases than the threshold triggering price decreases. In other words, it would imply that in absolute values, the threshold associated to price increases is smaller than the threshold associated to price decreases. If we examine the median values of the thresholds for price decreases and increases, we can note that on Monday, Tuesday and Wednesday there seems to be some asymmetry in price changes. The difference appears a little larger for unleaded petrol around 0.2 and $0.1-0.15$ for diesel prices. In other days, the difference is smaller (less than 0.1 ) but the direction of the asymmetry is also reversed. If we analyze estimation results obtained from a fixed menu cost model, we find a small downward asymmetry for unleaded petrol but not for diesel prices.

More formally, to assess the degree of asymmetry in price changes, we test that the difference between thresholds trigerring price increases and decreases is significant at each day (for every 
gas station) using a Wald test $\left(\gamma_{s}+\gamma_{S}=0\right.$ versus $\left.\gamma_{s}+\gamma_{S}>0\right)$. Table 8 summarizes the proportion of firms for which the asymmetry is significant. At a $5 \%$-level, we find that only between $15 \%$ and $20 \%$ of gas stations selling diesel have asymmetric thresholds on Monday, Tuesday or Wednesday. This proportion is a little higher for unleaded petrol (slightly above $20 \%$ ). At a $1 \%$ level, the proportion is smaller for diesel prices. If we consider Thursday, Friday and Saturday, the proportion of asymmetric firms is lower close to $8 \%$ for diesel and $10 \%$ for unleaded petrol. We also find that asymmetric behaviour is more frequent in supermarkets than in other gas stations. Besides, the proportion of gas stations which are downward asymmetric (at a $5 \%$ level) for at least 3 days of the week is equal to $5.5 \%$ for diesel and $11.8 \%$ for unleaded petrol; if we consider four days of asymmetric behaviour those proportions are $1.1 \%$ and $4.4 \%$. To compare those results, we run the same test on the standard fixed menu cost model and we find a little less than $6 \%$ of gas stations have an asymmetric behaviour for diesel prices and $7.1 \%$ for unleaded petrol. Overall, we do not find strong evidence in favor of asymmetry in price setting behaviour of French gas stations.

\subsection{Fit of the model}

In this subsection, we assess the goodness of fit of our model by testing its ability to replicate some aggregate moments and the distribution of price changes. We run Monte Carlo simulations on the basis of our parameter estimates and explanatory variables are taken at their sample values. We simulate each price trajectory 150 times using our model. Then, we compute aggregate statistics like the frequency of price changes, the average price increase and decrease, we also display the whole distribution of price changes. Moreover, we compare the simulated statistics obtained with our time-varying $(S, s)$ model with aggregate statistics obtained using estimates from two other models $\left(\mathrm{Calvo}^{24}\right.$ and fixed $(S, s)$ model $^{25}$ (see estimation results in Tables B and C in Appendix)).

\footnotetext{
${ }^{24}$ We here suppose that price changes are only by an idiosyncratic process. Prices are modified only if the random process is above a certain threshold. This threshold (which is estimated for every gas stations) determines the exogenous probability of price change.

${ }^{25}$ In this model, the threshold trigerring price changes does not vary over time and the variance of shock $\varepsilon_{2}$ is set to zero.
} 
Results are summarized in Tables 9 and 10 and on Figures 5 and 6. First, the Calvo model does better in reproducing the average frequency of price changes (between $11 \%$ and $10.5 \%$ of price changes in our simulations versus $11 \%$ and $10 \%$ in the sample for diesel and unleaded petrol respectively). The two menu cost models overestimate the frequency of price changes but time-varying $(S, s)$ model is closer than the fixed $(S, s)$ model. The main drawback of the Calvo model is that it is unable to predict that the frequency of price changes will move with the Rotterdam market. Second, on the size of price changes, the Calvo model and the variable $(S, s)$ model are closer to the sample average than the fixed $(S, s)$ model which predicts that a small majority of price changes are larger than $5 \%$ in absolute values. If we examine more closely the simulated distributions of price changes, the Calvo model is able to match quite correctly the distribution of actual price changes but cannot reproduce the small proportion of small price changes contrary to the time-varying $(S, s)$ model (Figures 5 and 6 ). Finally, the variable menu cost model is able to predict systematic changes in frequencies of price changes over the week. The fixed $(S, s)$ model would predict "seasonal" price changes over the week if only they are observed in Rotterdam prices which is not the case. By construction, the Calvo model cannot reproduce this fact.

\section{Aggregate dynamic response of gasoline prices}

In this section, we run several simulation exercises to assess the speed and the aggregate response of gasoline prices to different shocks to the Rotterdam wholesale prices.

\subsection{Simulation exercise}

Our simulation exercise consists of two steps: first we simulate individual price trajectories using our parameter estimates then aggregate those trajectories to calculate a simulated inflation rate. First, for all gas stations present in our sample, we simulate individual trajectories of prices. For that, we use parameter estimates obtained for every gas stations and run Monte Carlo simulations. Shocks $\varepsilon_{1 i, t}$ and $\varepsilon_{2 i, t}$ are drawn from two independent i.i.d. normal distributions with mean 0 and variances $\widehat{\sigma_{1 i}}$ and $\widehat{\sigma_{2 i}}$. We also assume Rotterdam wholesale prices to be 
constant, price decisions are only driven by the two idiosyncratic shocks. ${ }^{26}$ Each individual price trajectory is simulated for 55 days and the first 15 days are dropped to eliminate some possible initial conditions issues. We simulate each trajectory 500 times. We then compute the log difference of simulated prices for all trajectories and calculate the average of those differences to obtain an aggregate inflation rate. Then, we run again the same exercise but we introduce a permanent shock on the wholesale gas price (i.e. compared to the previous exercise, we consider that at date 16, Rotterdam prices increase by a given percentage). We consider different shocks on the wholesale Rotterdam prices: $-1 \%,+1 \%,+2 \%$ and $+5 \%$. For each experiment, we calculate the average aggregate inflation rate. Finally, we compute the difference between the average inflation rates obtained including exogenous shocks with the aggregate inflation rate obtained without any shock. This difference will capture the aggregate response of inflation to different shocks. To compare the aggregate response of prices in our time-varying threshold model, we run similar simulation exercises considering two limiting cases of our flexible threshold model, the Calvo model and the constant $(S, s)$ model $^{27}$. For that we use parameter estimates obtained for our two other models (see estimation results in Tables B and C in Appendix). ${ }^{28}$

\subsection{Results}

Figure 7 displays the inflation response of diesel and unleaded petrol prices to a $1 \%$-shock on Rotterdam prices in the three models. In all three models the long-term impact of the shock is exactly equal to the average value of $\beta$ (i.e. 0.77 for diesel and 0.67 for unleaded petrol). Retail prices adjust rather shortly after the shock (about 10 days for a complete adjustment). Table 10 provides some details on the delay of adjustment of retail prices, it gives the proportion of

\footnotetext{
${ }^{26}$ We also run similar exercises but considering a positive or negative exogenous trend in Rotterdam prices and results remain quite similar for the speed of adjustment.

${ }^{27}$ In the Calvo model, we estimate the model assuming that the decision of price change does not depend on the frictionless price but is only driven by a constant that is estimated. In the constant $(\mathrm{S}, \mathrm{s})$ model, we estimate a constrained model where the thresholds are constant over the days of the week and the variance of the shock on thresholds is zero.

${ }^{28}$ We run different simulation exercises assuming that the initial shock occurs at different days of the week but results appear rather similar.
} 
the shock absorbed in inflation after a certain duration in days. Using the variable $(S, s)$ model as a DGP for the simulations and a 1\%-shock, we find for example that about $40 \%$ of the total adjustment is achieved the day after the shock. We observe that 5 days after the shock about $90 \%$ of the total response of retail gasoline prices is observed and $95 \%$ of the total response is incorporated into prices after 2 weeks. There are some differences in the transmission delay of a shock between the different models used as DGP for the simulation. The transmission is shorter in the case of the constant $(S, s)$ model and longer in the Calvo model: $95 \%$ of the total response is obtained after 3 days in a constant $(S, s)$ model versus 15 days in the Calvo model (Figure 7). The time-varying threshold model appears as an intermediate case. Those differences in the delay to incorporate shocks are consistent with the macro literature on stateversus time-dependent models.

To understand those differences, Figure 10 illustrates the response of the frequency of price changes to a $1 \%$-shock on Rotterdam prices. In the Calvo model, the probability of price change is constant over time and exogenous, so it is not modified after a shock on Rotterdam price. Consequently, firms will change their prices gradually, the day after a shock $23 \%$ of firms will change their prices, at day 2 , among the $77 \%$ of firms which did not changed their prices before, $23 \%$ will change their prices (i.e. $18 \%$ of total firms)... In our simulation exercise, the frequency of price changes does not respond to shock on Rotterdam market prices with the Calvo model (Figure 8); the inflation adjustment comes from the size of price changes when prices are modified. In a standard menu cost, as explained by Caballero and Engel (2007), the reaction is quicker because of a selection effect: firms adjusting their prices are those the closest to the threshold and prices are modified, the size of price changes is equal to the size of the band (either $-S$ if it is a price decrease and $-s$ if it is a price increase). This implies a quick increase in the frequency of price changes (Figure 8 ). The random $(S, s)$ model allows to reduce the selection effect and makes the adjustment delay longer. If $\sigma_{2}$ is extremely high, price changes are not driven any more by changes in fundamentals but only by idiosyncratic shocks on the adjustment cost and in that case, the model is very close to the Calvo model. In our simulation exercise with a time-varying $(S, s)$ model, the frequency of price changes responds more slowly than in the case with a fixed $(S, s)$ model. However, the difference is quite small implying that 
the estimated time-varying model behaves quite closely to the fixed menu cost model in terms of frequency of price changes.

Figure 9 shows the inflation response of retail fuel prices to different market price shocks using the time-varying threshold model. First, the long term response is perfectly proportional to the shock: for diesel, after a $1 \%$-shock we obtain a response of 0.77 , with the $2 \%$-shock a response equal to $1.54 \%$ and with the $5 \%$-shock a response equal to $3.85 \%$. Second, a larger shock is incorporated more quickly (Figure 9). For diesel prices, a 5\%-shock on Rotterdam prices is almost fully incorporated in 5 days ( $95 \%$ of the shock) whereas 5 days after the shock less than $90 \%$ of the total response to the shock was incorporated in the case with $1 \%$ - and $2 \%$ shocks. For unleaded petrol prices, we obtain similar conclusions (Table 10). However, shocks are slightly more quickly incorporated in diesel prices than in unleaded petrol prices. The fact that retail prices react more quickly to larger shocks can be rationalized by the selection effect: the proportion of firms adjusting in a menu cost model is equal to the proportion of firms closest to the threshold and when they adjust those firms fully incorporate the shock. So, when the shock is larger, the number of firms adjusting their prices is larger (see Figure 10 for an illustration in our simulation exercise). This implies that the shock is more quickly incorporated into prices. On the contrary, in the Calvo model, there is no selection effect and the number of firms adjusting after a shock does not vary. So, the delay in reaction of retail prices to a market price shock will be exactly the same for all types of shocks.

Finally, we find no asymmetry in the aggregate response of retail gasoline prices to a market Rotterdam price shock. To test the presence of this asymmetry, we run simulations with a positive and a negative 1\%-shock on Rotterdam prices for diesel and unleaded petrol prices. As expected, Table 10 shows no difference in the speed of reaction of retail prices to a positive or a negative market price shock. In all cases and for all models considered, after a positive or a negative shock, we find very similar delays in the transmission of shocks. The only case where we can observe an asymmetry for unleaded petrol prices is at date +1 for time-varying threshold model, but it is small. This result is very consistent with outcomes of the tests of asymmetry in the thresholds. The proportion of firms with some asymmetries is rather limited and when asymmetries exist, their amplitude is small. 


\section{Conclusion}

In this paper, we examine the degree of price rigidity in French gas stations using a data set containing millions of price quotes collected at a daily frequency on the period between January 2007 and June 2009.

We first provide some new findings on the price setting behaviour of gas stations. Gasoline prices are modified frequently and firms are more likely to change their prices on Tuesdays and Fridays than on Saturdays, Sundays or Mondays. Price decreases are as frequent as price increases. The average size of price changes is larger than the average wholesale price change. Moreover, the distribution of price changes exhibits an $M$-shape where small price changes are quite scarce. This pattern of the distribution of price changes is consistent with predictions of a menu-cost model and contrasts with most empirical studies using individual CPI price quotes.

In this paper, we assess the degree of pass-through of costs to gasoline prices using price rigidity models. Our baseline model is a time-varying $(S, s)$ model which allows us to be rather flexible to replicate the infrequency of price changes and the distribution of price changes. We find that the degree of pass-through of wholesale market prices to retail gasoline prices is lower than 1 but consistent with the share of wholesale gasoline cost in total costs: 0.77 on average for diesel prices and 0.67 for unleaded petrol prices. This pass-through is somewhat larger in supermarkets than in other gas stations. Moreover, competition and local variables play a significant role to explain differences in pricing strategies among firms. Lastly we find that thresholds trigerring price changes are rather large on average but vary substantially over time. Finally, we simulate the aggregate response to shocks of gasoline retail prices. We find that the adjustment of fuel prices to market wholesale price shocks is quick. We also compare response obtained with alternative models of price rigidity: the longest response is obtained with the Calvo model where the delay for a full response is close to 3 weeks.

We test for the asymmetry in the response of retail gasoline prices to market wholesale price shock. We assess whether thresholds trigerring price increases and decreases are different. A larger threshold for price decrease implies that firms react more slowly to a decrease in costs. A small proportion of gas stations show some asymmetry in their price setting behaviour and 
when it is the case, the asymmetry is small. All in all, in our simulation exercises, the speed of reaction of retail prices to a comparable positive or negative wholesale price shock is the same. 


\section{References}

Alvarez F. , Lippi, F., and Paciello L. (2011) Optimal Price Setting with Observation and Menu Costs., Quarterly Journal of Economics, vol. 126(4), 1909-1960.

Asplund, M., Eriksson R. and Friberg, R. (2000) Price Adjustments by a Gasoline Retail Chain, Scandinavian Journal of Economics, vol. 102(1), 101-21.

Audenis C., Biscourp P. and Riedinger N. (2002) Le prix des carburants est plus sensible à une hausse qu'à une baisse du brut, Economie et Statistique 359-360.

Bils M. and Klenow P.J. (2004) Some Evidence on the Importance of Sticky Prices, Journal of Political Economy, 112, 947-985.

Caballero R. J. and Engel E.M. (1999) Explaining Investment Dynamics in U.S. Manufacturing: A Generalized $(S, s)$ Approach, Econometrica, 67, 4, 783-826.

Caballero R. J. and Engel E.M. (2007) Price Stickiness in Ss Models: New Interpretations of Old Results, Journal of Monetary Economics 54, Supplement 1, 100-121.

Calvo G. (1983) Staggered Prices in a Utility Maximising Framework, Journal of Monetary Economics, 12, 383-398.

Cavallo A. and Rigobon R. (2011) The Distribution of the Size of Price Changes, NBER Working Paper $\mathrm{n}^{\circ} 16760$.

Cecchetti S. (1986) The Frequency of Price Adjustment, Journal of Econometrics, 31, 255-274.

Davis M. C. (2007) The Dynamics of Daily Retail Gasoline Prices, Managerial and Decision Economics, vol. 28, Issue 7, 713-722.

Davis M. C. and Hamilton J. D (2004) Why Are Prices Sticky? The Dynamics of Wholesale Gasoline Prices, Journal of Money, Credit and Banking, vol. 36(1), 17-37.

Dhyne E., Álvarez L. J., Le Bihan H., Veronese G., Dias D., Hoffmann J., Jonker N., Lünnemann P., Rumler F. and Vilmunen J. (2006) Price Setting in the Euro Area: Some 
Stylised Facts from Individual Consumer Price Data, Journal of Economic Perspectives, 20, 2, 171-192.

Dhyne E., Fuss C., Pesaran H. and Sevestre P. (2011) Lumpy Price Adjustments: a Microeconomic Analysis, Journal of Business, Economics and Statistics, vol 29 n4, 529-540.

Dixit A. (1991) Analytical Approximations in Models of Hysteresis., Review of Economic Studies, $58,141-151$.

Dotsey M., King R. and Wolman A. (1999) State-Dependent Pricing and the General Equilibrium Dynamics of Money and Output, Quarterly Journal of Economics, 114, 655-690.

Douglas C. and Herrera A. M. (2010) Why are Gasoline Prices Sticky? A Test of Alternative Models of Price Adjustment, Journal of Applied Econometrics, Vol. 25, No. 6, 903-928.

Fougère D., Gautier E. and Le Bihan H. (2010) Restaurant Prices and the Minimum Wage, Journal of Money, Credit and Banking, Vol 42, 1199-1234.

Fougère D., Le Bihan H. and Sevestre P. (2007) Heterogeneity in Consumer Price Stickiness: a Microeconometric Investigation, Journal of Business and Economics Statistics, 25, 247-264.

Frey G. and Manera M. (2007) Econometric Models Of Asymmetric Price Transmission, Journal of Economic Surveys, vol. 21(2), 349-415.

Gautier E. and Le Bihan H. (2011) Time-Varying (S, s) Band Models: Properties and Interpretation, Journal of Economic Dynamics and Control, vol. 35(3), 394-412.

Golosov M. and Lucas R. (2007) Menu Costs and Phillips Curves, Journal of Political Economy, 115, 171-199.

Hansen P. (1999) Frequent Price Changes under Menu Costs, Journal of Economic Dynamics and Control, 23, 1065-1076.

Hosken D. S., McMillan R.S.,and Taylor C.T. (2008) Retail Gasoline Pricing: What do we know?, International Journal of Industrial Organization, vol. 26, 1425-1436. 
Klenow P. and Kryvtsov O. (2008) State-Dependent or Time-Dependent Pricing: Does It Matter for Recent U.S. Inflation?, Quarterly Journal of Economics, 123, 863-904.

Knotek E. S. II (2010) The Roles of Price Points and Menu Costs in Price Rigidity, Research Working Paper RWP 10-18, Federal Reserve Bank of Kansas City.

Levy D., Lee D., Chen H., Kauffman R. and Bergen M. (2011) Price Points and Price Rigidity, Review of Economics and Statistics, vol. 93(4), 1417-1431.

Meyler, A. (2009) The Pass-Through of Oil Prices into Euro Area Consumer Liquid Fuel Prices in an Environment of High and Volatile Oil Prices, Energy Economics, vol. 31(6), 867-881.

Müller G., Bergen M., Dutta S. and Levy D. (2010) Holiday Non-Price Rigidity and Cost of Adjustment, Economica, Vol. 77, n 305,172-198.

Nakamura E. and Steinsson J. (2008) Five Facts About Prices: A Reevaluation of Menu Cost Models, Quarterly Journal of Economics, 123(4), 1415-1464

Ratfai A. (2006) Linking Individual and Aggregate Price Changes, Journal of Money Credit and Banking, 38, 2199-2224.

Sheshinski E. and Weiss Y. (1977) Inflation and Costs of Price Adjustment, Review of Economic Studies, 44(2), 287-303.

Vermeulen P., Dias D., Dossche M., Gautier E., Hernando I., Sabbatini R., and Stahl H. (2012) Price Setting in the Euro Area: Some Stylised Facts from Individual Producer Price Data, Journal of Money, Credit and Banking, Vol. 44 no.8 (December 2012) 1631-1650.

Woodford, M. (2009) Information-Constrained State-Dependent Pricing. Journal of Monetary Economics 56(S), 100-124.

Wooldridge J. M. (2002) Econometric Analysis of Cross Section and Panel Data, MIT Press.

Zbaracki M. J., Ritson M., Levy D., Dutta S. and Bergen M. (2004) Managerial and Customer Costs of Price Adjustment: Direct Evidence from Industrial Markets, Review of Economics and Statistics, 86, 514-533. 
Table 1: Price durations (in days) and frequency of price changes (in \%)

\begin{tabular}{lrrrrr}
\hline \hline & Nb obs. & Mean & Q25 & Q50 & Q75 \\
\hline Price duration & & & & & \\
- Diesel & & & & & \\
$\quad$ individual price trajectories & $1,315,188$ & 5.23 & 2.00 & 4.00 & 7.00 \\
$\quad$ average by gas station & 10,161 & 6.64 & 4.61 & 6.05 & 8.13 \\
- Unleaded Petrol & & & & & \\
$\quad$ individual price trajectories & $1,213,842$ & 5.58 & 2.00 & 4.00 & 7.00 \\
$\quad$ average by gas station & 10,013 & 7.02 & 4.95 & 6.41 & 8.54 \\
\hline Frequency of price changes & & & & & \\
- Diesel & & & & & \\
$\quad$ Total & 10,161 & 17.62 & 11.82 & 16.25 & 21.50 \\
Increase & 10,161 & 8.71 & 5.83 & 8.13 & 10.78 \\
Decrease & 10,161 & 8.91 & 5.84 & 8.15 & 10.91 \\
- Unleaded Petrol & & & & & \\
Total & 10,013 & 16.52 & 11.19 & 15.27 & 20.00 \\
Increase & 10,013 & 8.74 & 6.07 & 8.21 & 10.56 \\
Decrease & 10,013 & 7.78 & 5.00 & 7.06 & 9.55 \\
\hline \hline
\end{tabular}

Note: For statistics on price durations, for the line "individual price trajectories", we compute statistics on the duration of price changes considering all individual price trajectories. For the line "average by gas station" but also for the frequency results, we compute firstly the average duration and frequency of price changes for each retailer. Then we compute the average of durations and frequencies. 
Table 2: Frequency of price changes over the week (in \%)

\begin{tabular}{lrrrrrr}
\hline \hline & \multicolumn{3}{c}{ Diesel } & & \multicolumn{3}{c}{ Unleaded Petrol } \\
& Total & Supermarkets & Other stations & Total & Supermarkets & Other stations \\
\hline Monday & 12.47 & 15.13 & 9.16 & 12.50 & 15.19 & 9.24 \\
Tuesday & 18.91 & 17.79 & 20.31 & 19.06 & 18.00 & 20.35 \\
Wednesday & 17.38 & 16.25 & 18.79 & 17.24 & 16.18 & 18.54 \\
Thursday & 16.80 & 15.78 & 18.08 & 16.74 & 15.60 & 18.13 \\
Friday & 21.02 & 22.14 & 19.62 & 21.23 & 22.33 & 19.89 \\
Saturday & 12.61 & 12.14 & 13.20 & 12.43 & 11.94 & 13.02 \\
Sunday & 0.80 & 0.77 & 0.84 & 0.80 & 0.76 & 0.84 \\
\hline \hline
\end{tabular}

Note: Frequencies are computed as the proportion of price changes (calculated over all price changes) at each day of the week. All columns sum to $100 \%$. 
Table 3: Size of price changes (in \%)

\begin{tabular}{|c|c|c|c|c|c|c|}
\hline & & $\mathrm{Nb}$ obs & Mean & Q25 & Q50 & Q75 \\
\hline \multicolumn{7}{|c|}{ Diesel prices } \\
\hline \multicolumn{7}{|l|}{ Increases } \\
\hline & Total & 639,966 & 2.33 & 1.15 & 1.77 & 2.80 \\
\hline & Supermarkets & 353,619 & 2.46 & 1.08 & 1.82 & 3.07 \\
\hline & Other gas stations & 286,347 & 2.16 & 1.21 & 1.71 & 2.54 \\
\hline \multicolumn{7}{|l|}{ Decreases } \\
\hline & Total & 651,078 & -2.41 & -3.06 & -1.87 & -1.16 \\
\hline & Supermarkets & 361,676 & -2.50 & -3.25 & -1.91 & -1.09 \\
\hline & Other gas stations & 289,402 & -2.30 & -2.86 & -1.85 & -1.23 \\
\hline \multicolumn{7}{|c|}{ Unleaded Petrol prices } \\
\hline \multicolumn{7}{|l|}{ Increases } \\
\hline & Total & 625,757 & 2.86 & 1.41 & 2.04 & 3.49 \\
\hline & Supermarkets & 340,431 & 3.07 & 1.32 & 2.22 & 3.89 \\
\hline & Other gas stations & 285,326 & 2.60 & 1.46 & 1.92 & 3.10 \\
\hline \multicolumn{7}{|l|}{ Decreases } \\
\hline & Total & 563,489 & -2.93 & -3.71 & -2.16 & -1.37 \\
\hline & Supermarkets & 311,985 & -3.08 & -4.00 & -2.22 & -1.24 \\
\hline & Other gas stations & 251,504 & -2.75 & -3.42 & -2.10 & -1.45 \\
\hline
\end{tabular}

Note: Frequencies are computed as the proportion of price changes at each day of the week. 
Table 4: Estimation results - Time-varying $(\mathrm{S}, \mathrm{s})$ model

\begin{tabular}{|c|c|c|c|c|c|c|c|c|c|c|c|}
\hline & & \multicolumn{5}{|c|}{ Diesel } & \multicolumn{5}{|c|}{ Unleaded petrol } \\
\hline & & Q25 & Q50 & Q75 & Mean & Stdc & Q25 & Q50 & Q75 & Mean & Stdc \\
\hline$\alpha$ & & 1.14 & 1.88 & 3.08 & 2.11 & 1.27 & -3.29 & -2.31 & -1.24 & -2.22 & 1.73 \\
\hline$\beta$ & & 0.71 & 0.80 & 0.83 & 0.77 & 0.07 & 0.63 & 0.68 & 0.72 & 0.67 & 0.06 \\
\hline$\sigma_{1}$ & & 1.42 & 1.55 & 1.71 & 1.58 & 0.28 & 1.68 & 1.88 & 2.11 & 1.92 & 0.41 \\
\hline \multirow{6}{*}{$\gamma_{s}$} & Mon. & -7.91 & -5.71 & -3.77 & -7.71 & 8.00 & -9.85 & -7.08 & -4.79 & -9.16 & 8.44 \\
\hline & Tues. & -5.74 & -4.09 & -2.96 & -4.56 & 2.67 & -7.29 & -5.16 & -3.78 & -5.74 & 3.19 \\
\hline & Wed. & -5.93 & -4.35 & -3.24 & -4.76 & 2.55 & -7.45 & -5.50 & -4.14 & -6.03 & 3.13 \\
\hline & Thu. & -6.19 & -4.57 & -3.38 & -5.02 & 2.97 & -7.67 & -5.72 & -4.27 & -6.31 & 3.79 \\
\hline & Fri. & -5.49 & -4.01 & -2.94 & -4.39 & 2.48 & -6.87 & -5.10 & -3.76 & -5.56 & 3.30 \\
\hline & Sat. & -7.68 & -5.46 & -3.76 & -7.51 & 7.75 & -9.52 & -6.99 & -4.87 & -9.11 & 8.39 \\
\hline \multirow{6}{*}{$\gamma_{S}$} & Mon. & 3.89 & 5.81 & 8.38 & 8.52 & 8.76 & 4.99 & 7.29 & 10.51 & 10.28 & 9.61 \\
\hline & Tues. & 3.09 & 4.24 & 5.89 & 4.72 & 2.97 & 3.98 & 5.41 & 7.56 & 6.14 & 4.50 \\
\hline & Wed. & 3.31 & 4.46 & 6.08 & 4.93 & 2.88 & 4.29 & 5.71 & 7.77 & 6.39 & 4.18 \\
\hline & Thu. & 3.29 & 4.52 & 6.18 & 5.03 & 3.16 & 4.29 & 5.79 & 7.88 & 6.56 & 4.61 \\
\hline & Fri. & 2.82 & 3.94 & 5.46 & 4.33 & 2.55 & 3.70 & 5.07 & 6.97 & 5.58 & 3.24 \\
\hline & Sat. & 3.69 & 5.36 & 7.58 & 7.50 & 7.97 & 4.88 & 6.97 & 9.68 & 9.38 & 8.89 \\
\hline$\sigma_{2}$ & & 2.52 & 3.11 & 3.82 & 3.18 & 1.03 & 3.12 & 3.82 & 4.74 & 3.98 & 1.33 \\
\hline
\end{tabular}

Note: We estimate for each individual gas station a time-varying $(\mathrm{S}, \mathrm{s})$ model and then compute statistics on the parameter estimates we obtained. We consider all gas stations with more than 400 individual observations of prices. For diesel prices, 7,917 values of parameters estimates are available and 7,211 for unleaded petrol prices. Observations on Sundays are excluded from the sample used for the estimation. 
Table 5: Estimation results - Time-varying (S,s) model - supermarkets versus other gas stations

\begin{tabular}{|c|c|c|c|c|c|c|c|c|c|}
\hline & & \multicolumn{4}{|c|}{ Diesel prices } & \multicolumn{4}{|c|}{ Unleaded petrol prices } \\
\hline & & \multicolumn{2}{|c|}{ Supermarkets } & \multicolumn{2}{|c|}{ Others } & \multicolumn{2}{|c|}{ Supermarkets } & \multicolumn{2}{|c|}{ Others } \\
\hline & & Mean & Stdc & Mean & Stdc & Mean & Stdc & Mean & Stdc \\
\hline$\alpha$ & & 1.47 & 0.89 & 2.75 & 1.27 & -2.75 & 1.45 & -1.70 & 1.82 \\
\hline$\beta$ & & 0.81 & 0.04 & 0.73 & 0.07 & 0.70 & 0.04 & 0.64 & 0.07 \\
\hline$\sigma_{1}$ & & 1.61 & 0.22 & 1.55 & 0.34 & 1.96 & 0.33 & 1.88 & 0.47 \\
\hline \multirow{5}{*}{$\gamma_{s}$} & Mon. & -5.80 & 5.63 & -9.63 & 9.44 & -7.12 & 5.76 & -11.18 & 10.03 \\
\hline & Tues. & -4.59 & 2.72 & -4.53 & 2.61 & -5.83 & 3.24 & -5.66 & 3.14 \\
\hline & Wed. & -4.83 & 2.54 & -4.69 & 2.55 & -6.17 & 3.15 & -5.90 & 3.10 \\
\hline & Thu. & -5.06 & 3.06 & -4.97 & 2.89 & -6.47 & 3.77 & -6.15 & 3.81 \\
\hline & Fri. & -4.17 & 2.64 & -4.62 & 2.28 & -5.32 & 3.33 & -5.79 & 3.25 \\
\hline \multirow{7}{*}{$\gamma_{S}$} & Sat. & -6.44 & 5.81 & -8.60 & 9.17 & -8.14 & 6.54 & -10.07 & 9.80 \\
\hline & Mon. & 6.24 & 6.11 & 10.82 & 10.29 & 7.68 & 6.82 & 12.85 & 11.15 \\
\hline & Tues. & 4.86 & 3.37 & 4.59 & 2.49 & 6.32 & 5.15 & 5.96 & 3.74 \\
\hline & Wed. & 4.99 & 2.93 & 4.97 & 3.14 & 6.54 & 4.04 & 6.25 & 4.32 \\
\hline & Thu. & 5.08 & 3.18 & 4.97 & 3.14 & 6.67 & 5.32 & 6.46 & 4.86 \\
\hline & Fri. & 4.07 & 2.46 & 4.59 & 2.60 & 4.34 & 3.14 & 5.84 & 3.32 \\
\hline & Sat. & 6.47 & 6.15 & 8.53 & 9.34 & 8.47 & 7.80 & 5.84 & 10.45 \\
\hline$\sigma_{2}$ & & 3.19 & 1.11 & 3.17 & 0.93 & 4.01 & 1.36 & 3.94 & 1.30 \\
\hline
\end{tabular}

Note: We estimate for each individual gas station a time-varying $(\mathrm{S}, \mathrm{s})$ model and then compute statistics on the parameter estimates we obtained. We consider all gas stations with more than 400 individual observations of prices. For diesel prices, 4,004 and 3, 913 values of parameters estimates are available for supermarkets and other stations respectively and 3,585 and 3,626 for unleaded petrol prices. Observations on Sundays are excluded from the sample used for the estimation. 
Table 6: Determinants of time-varying (S,s) model parameters - Diesel

\begin{tabular}{|c|c|c|c|}
\hline & $\alpha_{i}$ & $\beta_{i}$ & $\frac{\left|s_{i}\right|+\left|S_{i}\right|}{2}$ \\
\hline Distance to closest supermarket gas station $(\mathrm{km})$ & $\begin{array}{c}0.012^{\star \star \star} \\
(0.003)\end{array}$ & $\begin{array}{c}-0.001^{\star \star \star} \\
(0.000)\end{array}$ & $\begin{array}{c}0.035^{\star \star \star} \\
(0.009)\end{array}$ \\
\hline Number of supermarket gas stations within $10 \mathrm{kms}$ & $\begin{array}{c}-0.009^{\star \star \star} \\
(0.002)\end{array}$ & $\begin{array}{c}0.001^{\star \star \star} \\
(0.000)\end{array}$ & $\begin{array}{c}-0.025^{\star \star \star} \\
(0.006)\end{array}$ \\
\hline Motorway & $\begin{array}{l}0.083 \\
(0.058) \\
\end{array}$ & $\begin{array}{c}-0.108^{\star \star \star} \\
(0.002)\end{array}$ & $\begin{array}{c}2.577^{\star \star \star} \\
(0.152)\end{array}$ \\
\hline Pricing points & $\begin{array}{l}0.010 \\
(0.027) \\
\end{array}$ & $\begin{array}{c}-0.008^{\star \star \star} \\
(0.001)\end{array}$ & $\begin{array}{c}0.905^{\star \star \star} \\
(0.072)\end{array}$ \\
\hline Households owning a car (\%) & $\begin{array}{c}-0.010^{\star \star \star} \\
(0.002)\end{array}$ & $\begin{array}{c}0.001^{\star \star \star} \\
(0.00)\end{array}$ & $\begin{array}{c}0.010^{\star \star} \\
(0.004)\end{array}$ \\
\hline Urban area with 20,000 to 100,000 inhabitants & $\begin{array}{l}-0.030 \\
(0.035)\end{array}$ & $\begin{array}{c}0.005^{\star \star \star} \\
(0.001)\end{array}$ & $\begin{array}{c}-0.457^{\star \star \star} \\
(0.092)\end{array}$ \\
\hline Urban area with more than 100,000 inhabitants & $\begin{array}{l}-0.040 \\
(0.037)\end{array}$ & $\begin{array}{c}0.005^{\star \star \star} \\
(0.001)\end{array}$ & $\begin{array}{c}-0.401^{\star \star \star} \\
(0.097)\end{array}$ \\
\hline Paris and its region & $\begin{array}{l}-0.039 \\
(0.128)\end{array}$ & $\begin{array}{l}-0.003 \\
(0.004)\end{array}$ & $\begin{array}{l}-0.433 \\
(0.333)\end{array}$ \\
\hline Unemployment rate $(\%)$ & $\begin{array}{c}-0.012^{\star \star \star} \\
(0.004)\end{array}$ & $\begin{array}{c}0.001^{\star \star \star} \\
(0.000)\end{array}$ & $\begin{array}{c}0.024^{\star \star} \\
(0.011)\end{array}$ \\
\hline Pump working with credit/debit cards & $\begin{array}{l}-0.037 \\
(0.026)\end{array}$ & $\begin{array}{c}0.003^{\star \star \star} \\
(0.001)\end{array}$ & $\begin{array}{l}0.049 \\
(0.067)\end{array}$ \\
\hline Store & $\begin{array}{c}0.162^{\star \star \star} \\
(0.036)\end{array}$ & $\begin{array}{c}-0.006^{\star \star \star} \\
(0.001)\end{array}$ & $\begin{array}{c}0.339^{\star \star \star} \\
(0.095)\end{array}$ \\
\hline Restaurant & $\begin{array}{l}-0.001 \\
(0.034)\end{array}$ & $\begin{array}{l}0.002 \\
(0.001)\end{array}$ & $\begin{array}{c}-0.385^{\star \star \star} \\
(0.088)\end{array}$ \\
\hline Car services & $\begin{array}{l}0.033 \\
(0.028)\end{array}$ & $\begin{array}{c}-0.003^{\star \star \star} \\
(0.001)\end{array}$ & $\begin{array}{c}-0.233^{\star \star \star} \\
(0.073)\end{array}$ \\
\hline Premium gasoline & $\begin{array}{c}0.110^{\star \star \star} \\
(0.039)\end{array}$ & $\begin{array}{c}-0.002 \\
(0.001)\end{array}$ & $\begin{array}{l}0.085 \\
(0.101) \\
\end{array}$ \\
\hline Adjusted $R^{2}$ & 0.525 & 0.810 & 0.377 \\
\hline Number of observations & 6,916 & 6,916 & 6,916 \\
\hline
\end{tabular}

Note: Columns report the OLS estimates for the time-varying $(\mathrm{S}, \mathrm{s})$ model parameters. "Urban area with less than 20,000 inhab." is used as reference. "Motorway" is a dummy variable equal to one if the gas station is on a motorway. "Pricing points" is a dummy variable equal to one if more than $95 \%$ of prices end by 0 or 9 . Local unemployment and share of households owning at least one car come from the census 2008. "Pump working with credit/debit cards", "Store", "Restaurant", "Car services" and "Premium gasoline" are dummy variables equal to one if the service is provided in the gas station. Dummy variables for 28 different brands and 22 regions are included. Significance level : ${ }^{\star \star \star} 1 \%,{ }^{\star \star} 5 \%,{ }^{\star} 10 \%$. 
Table 7: Determinants of time-varying (S,s) model parameters - Unleaded petrol

\begin{tabular}{|c|c|c|c|}
\hline & $\alpha_{i}$ & $\beta_{i}$ & $\frac{\left|s_{i}\right|+\left|S_{i}\right|}{2}$ \\
\hline Distance to closest supermarket gas station $(\mathrm{km})$ & $\begin{array}{c}0.015^{\star \star \star} \\
(0.005)\end{array}$ & $\begin{array}{c}-0.000 \\
(0.000)\end{array}$ & $\begin{array}{l}0.006 \\
(0.011)\end{array}$ \\
\hline Number of supermarket gas stations within $10 \mathrm{kms}$ & $\begin{array}{c}-0.004 \\
(0.004)\end{array}$ & $\begin{array}{c}0.001^{\star \star \star} \\
(0.000)\end{array}$ & $\begin{array}{c}-0.036^{\star \star \star} \\
(0.008)\end{array}$ \\
\hline Motorway & $\begin{array}{c}0.634^{\star \star \star} \\
(0.097)\end{array}$ & $\begin{array}{c}-0.064^{\star \star \star} \\
(0.003)\end{array}$ & $\begin{array}{c}3.647^{\star \star \star} \\
(0.196)\end{array}$ \\
\hline Pricing points & $\begin{array}{c}0.139^{\star \star \star \star} \\
(0.047)\end{array}$ & $\begin{array}{c}-0.007^{\star \star \star} \\
(0.001)\end{array}$ & $\begin{array}{c}1.155^{\star \star \star} \\
(0.094)\end{array}$ \\
\hline Households owning a car $(\%)$ & $\begin{array}{c}-0.010^{\star \star \star} \\
(0.003)\end{array}$ & $\frac{0.000^{\star \star \star}}{(0.000)}$ & $\begin{array}{l}0.006 \\
(0.006)\end{array}$ \\
\hline Urban area with 20,000 to 100,000 inhabitants & $\begin{array}{l}0.068 \\
(0.059)\end{array}$ & $\begin{array}{c}0.008^{\star \star \star} \\
(0.002)\end{array}$ & $\begin{array}{c}-0.570^{\star \star \star} \\
(0.120)\end{array}$ \\
\hline Urban area with more than 100,000 inhabitants & $\begin{array}{c}-0.042 \\
(0.063)\end{array}$ & $\frac{0.008^{\star \star \star}}{(0.002)}$ & $\begin{array}{c}-0.717^{\star \star \star} \\
(0.127)\end{array}$ \\
\hline Paris and its region & $\begin{array}{l}0.186 \\
(0.247)\end{array}$ & $\begin{array}{l}0.006 \\
(0.007)\end{array}$ & $-1.047^{\star \star}$ \\
\hline Unemployment rate $(\%)$ & $\begin{array}{c}-0.012^{\star} \\
(0.007)\end{array}$ & $\begin{array}{c}0.001^{\star \star \star} \\
(0.000)\end{array}$ & $\begin{array}{l}0.023 \\
(0.014)\end{array}$ \\
\hline Pump working with credit/debit cards & $\begin{array}{c}-0.060 \\
(0.043)\end{array}$ & $\begin{array}{c}0.002^{\star} \\
(0.001)\end{array}$ & $\begin{array}{l}0.048 \\
(0.088)\end{array}$ \\
\hline Store & $\begin{array}{l}0.065 \\
(0.062)\end{array}$ & $\begin{array}{c}-0.008^{\star \star \star} \\
(0.002)\end{array}$ & $\underset{(0.125)}{0.378^{\star \star \star}}$ \\
\hline Restaurant & $\begin{array}{c}-0.026 \\
(0.057)\end{array}$ & $\begin{array}{c}0.003^{\star \star} \\
(0.001)\end{array}$ & $\begin{array}{c}-0.405^{\star \star \star} \\
(0.115)\end{array}$ \\
\hline Car services & $\begin{array}{c}-0.017 \\
(0.047)\end{array}$ & $\begin{array}{c}-0.003^{\star \star} \\
(0.001)\end{array}$ & $\begin{array}{c}-0.203^{\star \star} \\
(0.096)\end{array}$ \\
\hline Premium gasoline & $\begin{array}{c}0.148^{\star \star} \\
(0.065)\end{array}$ & $\begin{array}{c}-0.001 \\
(0.002)\end{array}$ & $\begin{array}{l}0.159 \\
(0.132) \\
\end{array}$ \\
\hline Adjusted $R^{2}$ & 0.300 & 0.659 & 0.375 \\
\hline Number of observations & 6,262 & 6,262 & 6,262 \\
\hline
\end{tabular}

Note: Columns report the OLS estimates for the time-varying $(\mathrm{S}, \mathrm{s})$ model parameters. "Urban area with less than 20,000 inhab." is used as reference. "Motorway" is a dummy variable equal to one if the gas station is on a motorway. "Pricing points" is a dummy variable equal to one if more than $95 \%$ of prices end by 0 or 9 . Local unemployment and share of households owning at least one car come from the census 2008. "Pump working with credit/debit cards", "Store", "Restaurant", "Car services" and "Premium gasoline" are dummy variables equal to one if the service is provided in the gas station. Dummy variables for 28 different brands and 22 regions are included. Significance level : ${ }^{\star \star \star} 1 \%,{ }^{\star \star} 5 \%,{ }^{\star} 10 \%$. 
Table 8: Proportion of gas stations with significant downward asymmetric reaction (Wald test $\gamma_{s}+\gamma_{S}>0$ )

\begin{tabular}{lrrrrrr}
\hline & \multicolumn{5}{c}{$5 \%$} & \multicolumn{3}{c}{$1 \%$} \\
& Total & $\begin{array}{c}\text { Super- } \\
\text { markets }\end{array}$ & $\begin{array}{c}\text { Other } \\
\text { stations }\end{array}$ & Total & $\begin{array}{r}\text { Super- } \\
\text { markets }\end{array}$ & Other \\
& & \multicolumn{5}{c}{ Diesel } \\
& & & & \\
Mon. & 16.46 & 24.10 & 8.64 & 9.65 & 15.04 & 4.14 \\
Tues. & 20.75 & 24.98 & 16.43 & 10.90 & 14.79 & 6.93 \\
Wed. & 17.97 & 17.48 & 18.48 & 8.87 & 9.44 & 8.28 \\
Thu. & 8.44 & 11.44 & 5.37 & 3.84 & 5.29 & 2.35 \\
Fri. & 6.85 & 8.44 & 5.21 & 3.47 & 4.17 & 2.76 \\
Sat. & 8.22 & 9.29 & 7.13 & 3.88 & 4.37 & 3.37 \\
Fixed Cost & 5.87 & 8.50 & 3.35 & 1.99 & 3.03 & 0.99 \\
\hline & & & Unleaded petrol & & \\
Mon. & 22.35 & 25.44 & 19.18 & 18.78 & 21.34 & 16.14 \\
Tues. & 21.07 & 24.26 & 17.77 & 15.17 & 18.61 & 11.63 \\
Wed. & 20.50 & 23.42 & 17.49 & 14.67 & 17.38 & 11.88 \\
Thu. & 11.65 & 13.28 & 9.97 & 8.45 & 9.95 & 6.90 \\
Fri. & 10.64 & 12.65 & 8.56 & 7.96 & 9.95 & 5.91 \\
Sat. & 13.73 & 14.67 & 12.76 & 11.08 & 11.89 & 10.25 \\
Fixed Cost & 7.14 & 10.10 & 4.25 & 2.32 & 3.37 & 1.28 \\
\hline \hline
\end{tabular}

Note: We compute the proportion of gas stations for which the hypothesis $\gamma_{s_{i}}+\gamma_{S_{i}}>0$ is accepted at a 5\%- and 1\%-levels. For the time-varying threshold models, we compute this test day by day (i) and for the fixed (S,s) model we test the hypothesis $\gamma_{s}+\gamma_{S}>0$. Sundays are excluded from the analysis. 
Table 9: Simulated aggregated statistics

\begin{tabular}{lrrrrrrrr}
\hline \hline & $F+$ & $F-$ & $d p-$ & $d p+$ & \multicolumn{3}{c}{$\begin{array}{c}\text { Prop. of }|d p| \\
\end{array}$} \\
& & & & & $<0.5 \%$ & $<1 \%$ & $>5 \%$ \\
\hline Diesel & & & & & & & \\
Sample & 10.66 & 10.92 & -2.40 & 2.38 & 8.86 & 23.94 & 8.96 \\
Variable menu cost & 13.08 & 13.11 & -2.84 & 2.90 & 9.30 & 18.65 & 12.45 \\
Fixed Menu Cost & 14.37 & 14.76 & -6.09 & 6.60 & 0.07 & 0.21 & 60.66 \\
Calvo & 11.23 & 11.18 & -2.43 & 2.46 & 17.34 & 30.61 & 10.46 \\
\hline Unleaded Petrol & & & & & & & \\
Sample & 10.27 & 9.15 & -2.96 & 2.91 & 6.78 & 17.00 & 14.52 \\
Variable menu cost & 12.07 & 12.36 & -3.39 & 3.51 & 7.71 & 15.20 & 21.83 \\
Fixed Menu Cost & 14.02 & 13.83 & -7.63 & 8.22 & 0.04 & 0.09 & 80.07 \\
Calvo & 10.62 & 10.37 & 2.99 & -2.87 & 14.52 & 25.78 & 17.07 \\
\hline \hline
\end{tabular}

Note: We compute simulated price trajectories using our parameter estimates and taking exogenous variables at their sample values. We then compute the frequencies of price increases and decreases for each gas station and calculate the average frequency of price increases and decreases $(F+$ and $F-)$. The same procedure is followed to calculate the average size of price changes $(d p-$ and $d p+)$ and the average proportion (Prop. of $|d p|$ ) of small and large price changes. We use simulations from the time-varying threshold model, the fixed (S,s) model and the "Calvo" model. Sundays are not considered. 
Table 10: Dynamic response of gasoline prices to shocks on wholesale market prices (Rotterdam)

\begin{tabular}{lccccc|cccc|cc}
\hline & & \multicolumn{5}{c|}{ Fixed (S,s) } & \multicolumn{3}{c|}{ Time-varying (S,s) } & \multicolumn{2}{c}{ Calvo } \\
& nb days & $-1 \%$ & $1 \%$ & $2 \%$ & $5 \%$ & $-1 \%$ & $1 \%$ & $2 \%$ & $5 \%$ & $1 \%$ & $-1 \%$ \\
\hline Diesel & & & & & & & & & & & \\
& 1 & 0.74 & 0.74 & 0.75 & 0.82 & 0.43 & 0.43 & 0.46 & 0.58 & 0.23 & 0.23 \\
& 2 & 0.90 & 0.90 & 0.91 & 0.95 & 0.63 & 0.63 & 0.66 & 0.77 & 0.40 & 0.40 \\
& 3 & 0.95 & 0.95 & 0.96 & 0.98 & 0.77 & 0.77 & 0.79 & 0.88 & 0.52 & 0.52 \\
& 5 & 0.98 & 0.98 & 0.98 & 1 & 0.87 & 0.87 & 0.89 & 0.95 & 0.69 & 0.69 \\
& 10 & 0.99 & 0.99 & 0.99 & 1 & 0.97 & 0.97 & 0.97 & 0.99 & 0.88 & 0.88 \\
& 15 & 0.99 & 0.99 & 0.99 & 1 & 0.99 & 0.99 & 0.99 & 1 & 0.95 & 0.95 \\
\hline \multirow{2}{*}{ Petrol } & & & & & & & & & & & \\
& 1 & 0.73 & 0.73 & 0.73 & 0.77 & 0.40 & 0.41 & 0.42 & 0.49 & 0.21 & 0.21 \\
& 2 & 0.89 & 0.89 & 0.89 & 0.92 & 0.61 & 0.61 & 0.62 & 0.70 & 0.37 & 0.37 \\
& 3 & 0.94 & 0.94 & 0.94 & 0.96 & 0.75 & 0.75 & 0.76 & 0.82 & 0.50 & 0.50 \\
& 5 & 0.97 & 0.97 & 0.97 & 0.99 & 0.86 & 0.86 & 0.87 & 0.91 & 0.67 & 0.67 \\
& 10 & 0.99 & 0.99 & 0.99 & 0.99 & 0.96 & 0.96 & 0.96 & 0.98 & 0.87 & 0.87 \\
& 15 & 0.99 & 0.99 & 0.99 & 1 & 0.99 & 0.99 & 0.99 & 0.99 & 0.94 & 0.94 \\
\hline \hline
\end{tabular}

Note: We compute simulated price trajectories using our parameter estimates and aggregate those price trajectories. Then we run the same exercise but adding a permanent shock on market prices. We compute the difference between the two aggregate price indices obtained. We then calculate the cumulated response of retail prices to a shock as the cumulated difference. Finally, we compute the ratio as the cumulated response after a certain duration from the date of the shock on the total response measured as the cumulated response after 45 days. We use simulations from the time-varying threshold model, the fixed $(\mathrm{S}, \mathrm{s})$ model and the "Calvo" model. 
Figure 1: Distribution of firm-level average durations of prices (in days)

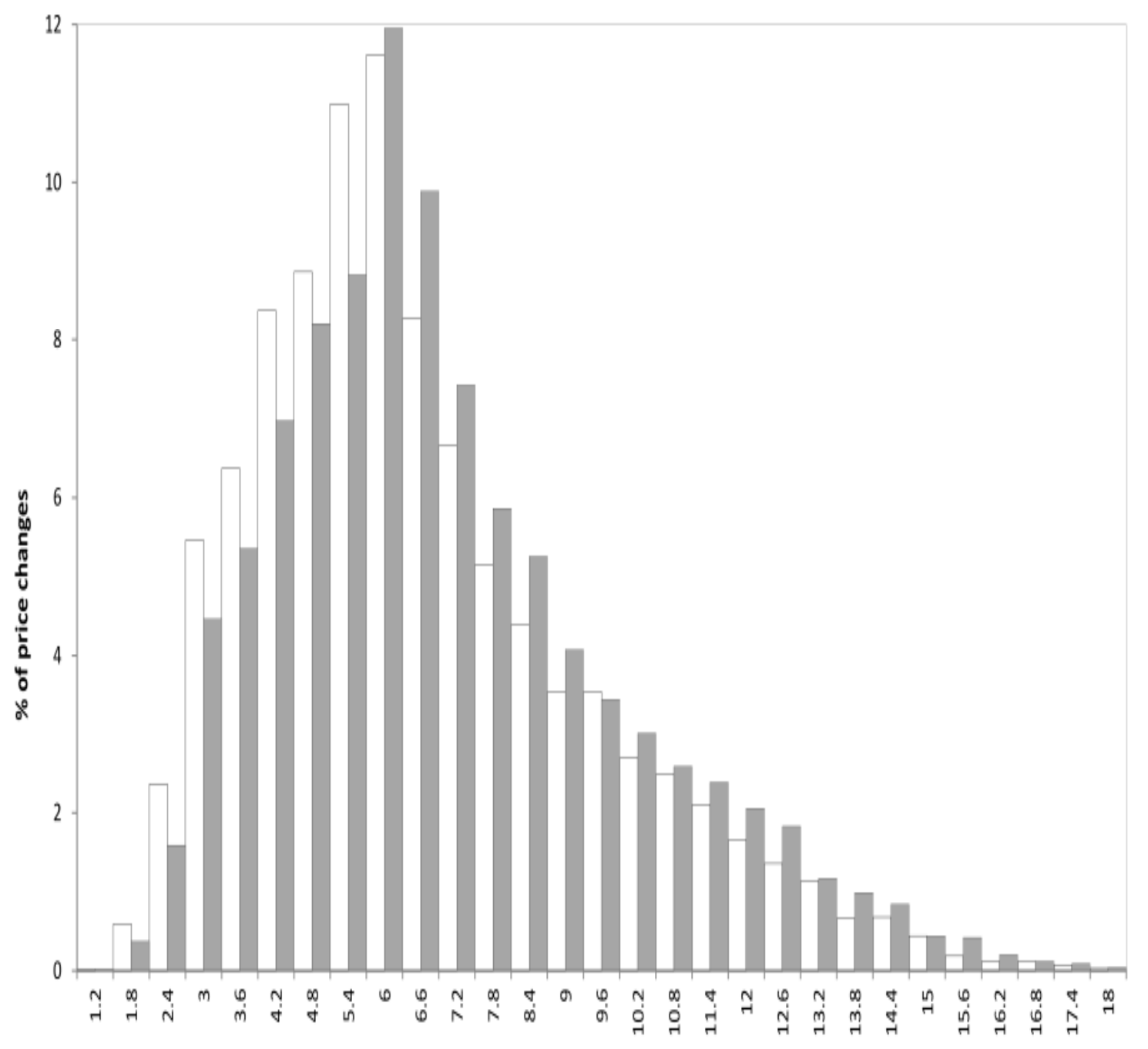

Average days between price changes

Note. Each observation is the average duration between two price changes calculated for every individual gas stations. Grey bars are for unleaded petrol prices and white bars are for diesel prices. 
Figure 2: Hazard rates for price changes

a) Diesel

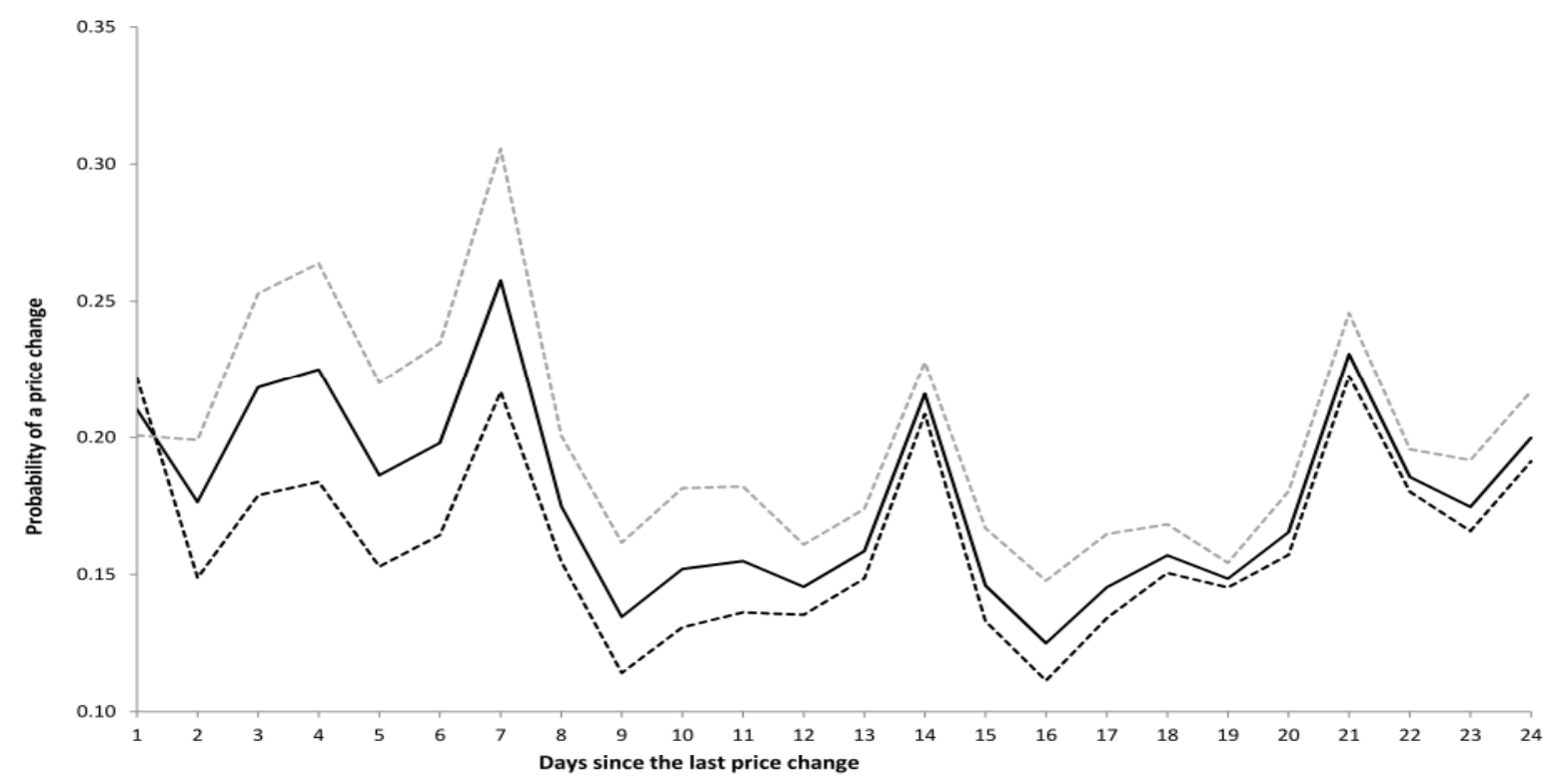

b) Unleaded petrol

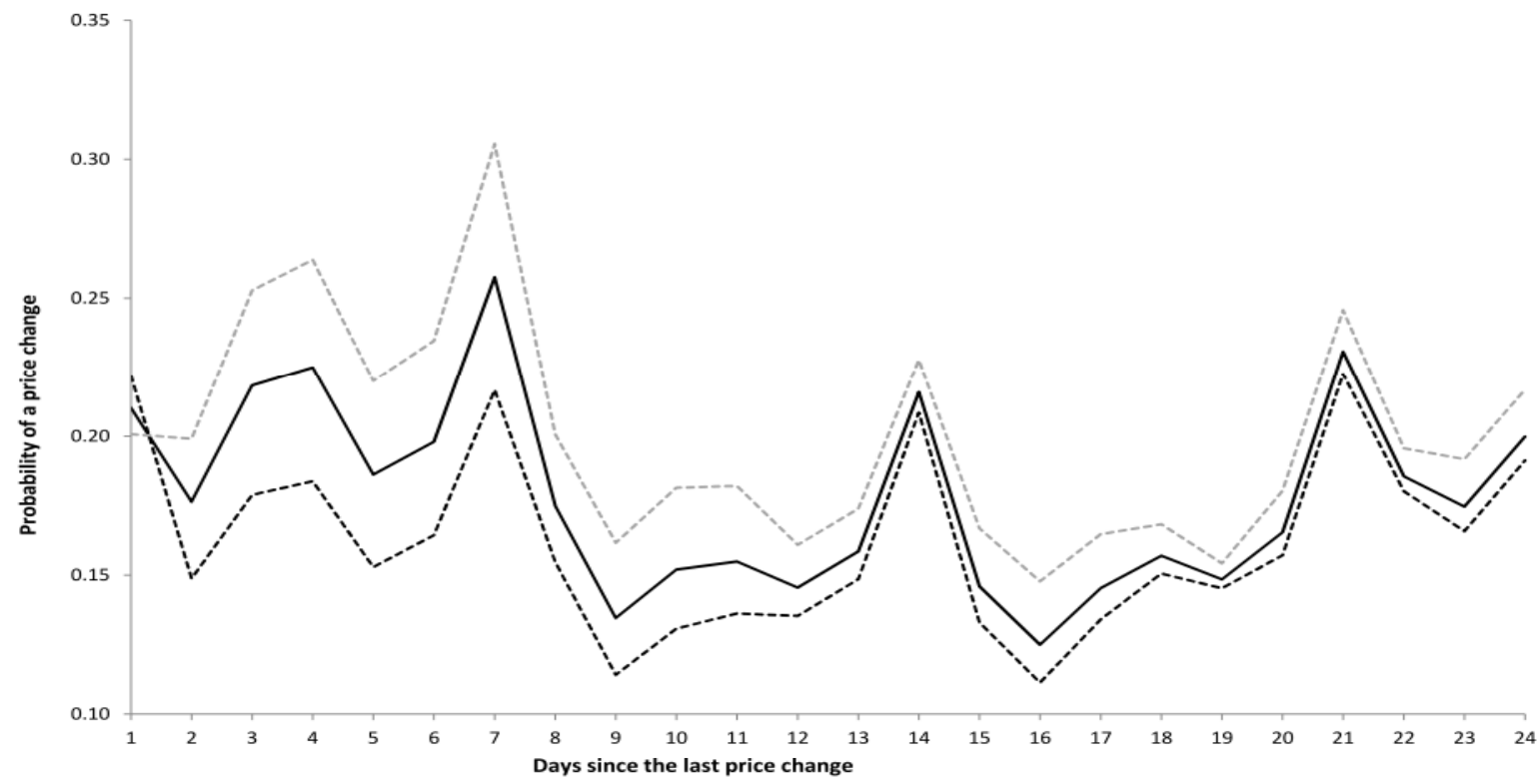

Note. Solid black line for all gas stations, dashed grey line for supermarkets, dashed black line for other gas stations. Left-censored price paths are excluded. All other price paths are taken into account. 
Figure 3: Distributions of individual retail price changes (in \%)

a) Diesel

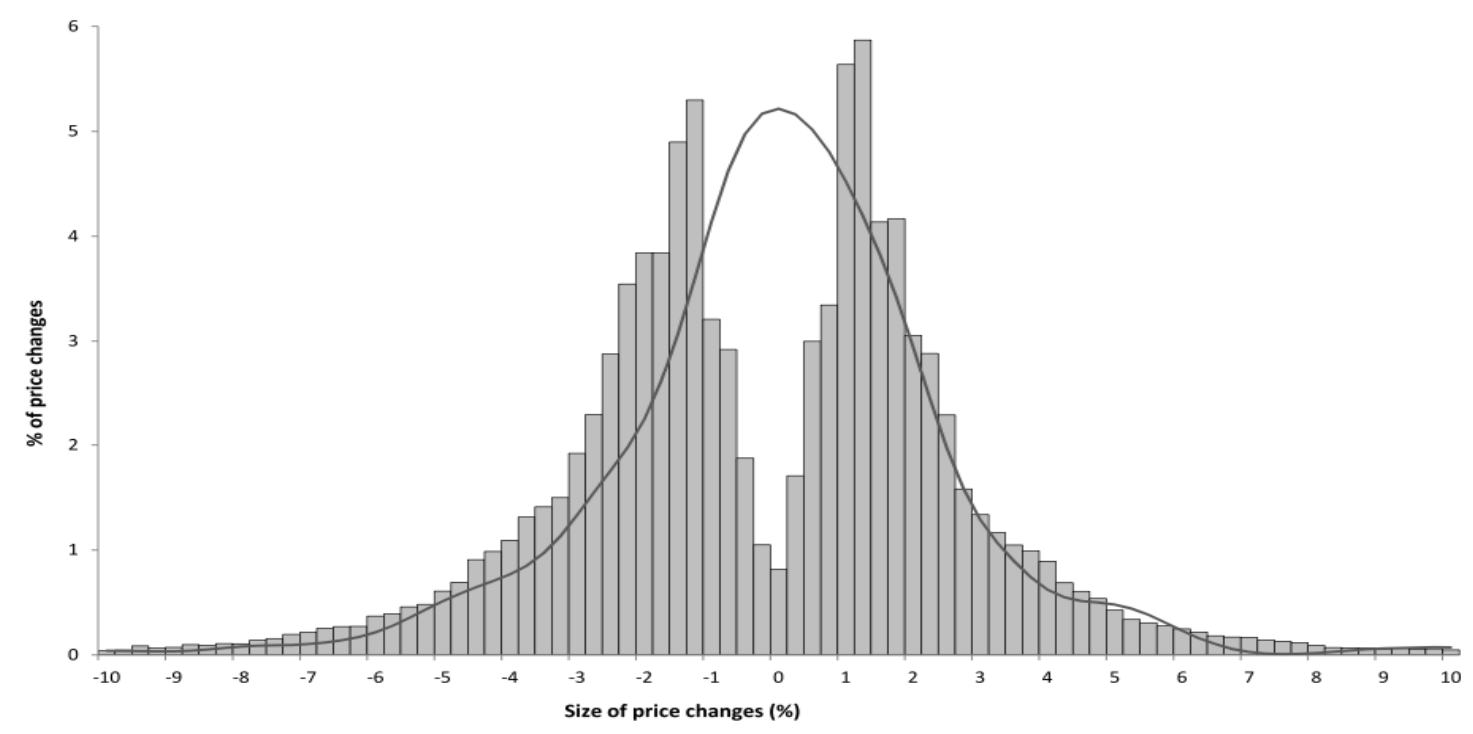

b) Unleaded petrol

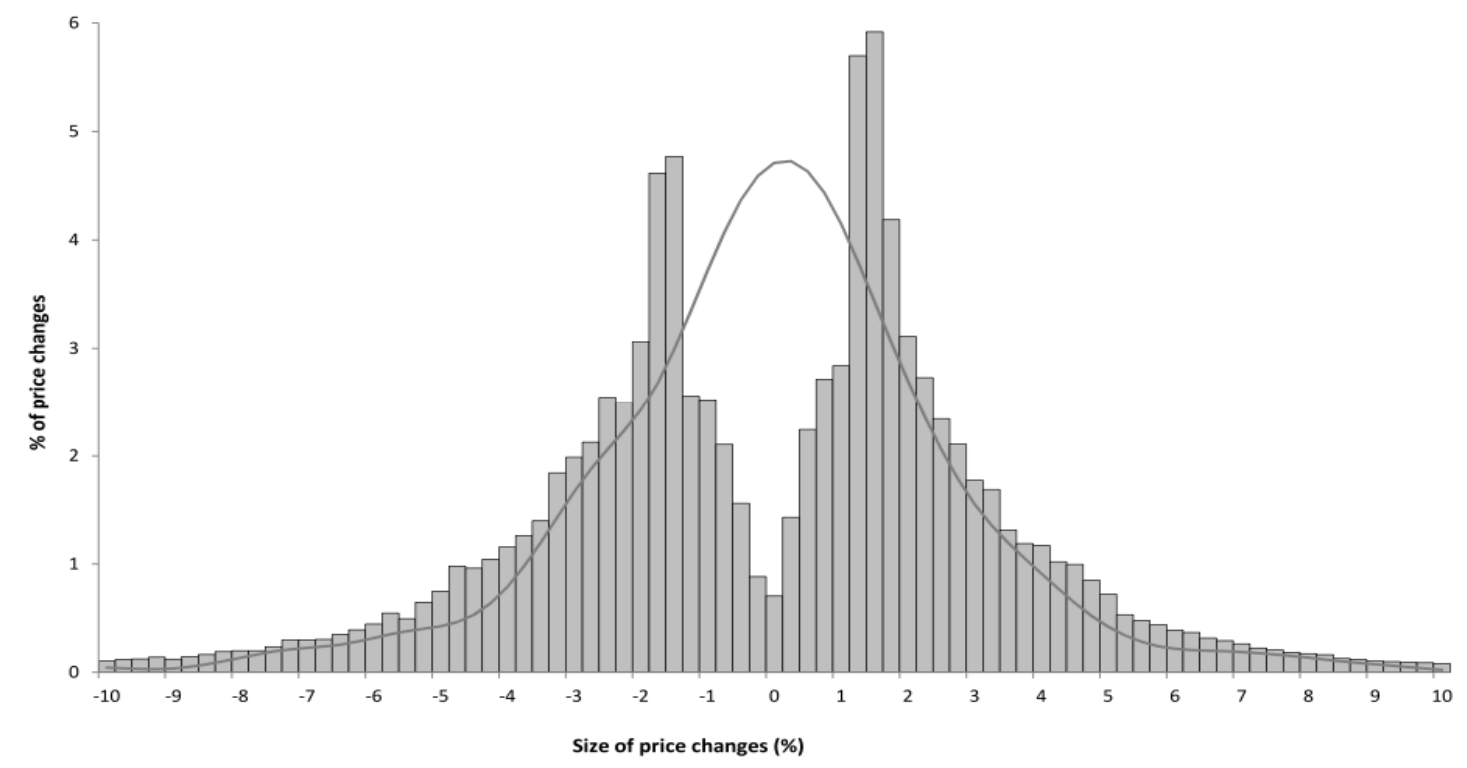

Note. Observations are individual price changes when prices are actually changed. Grey bars represent the distribution of retail price changes and grey lines are the kernel density estimators for distributions of Rotterdam price changes. Retail price changes are calculated using prices excluding taxes. 
Figure 4: Distribution of $\beta_{i}$ (degree of pass-through) using the time-varying threshold model

Panel a) Diesel

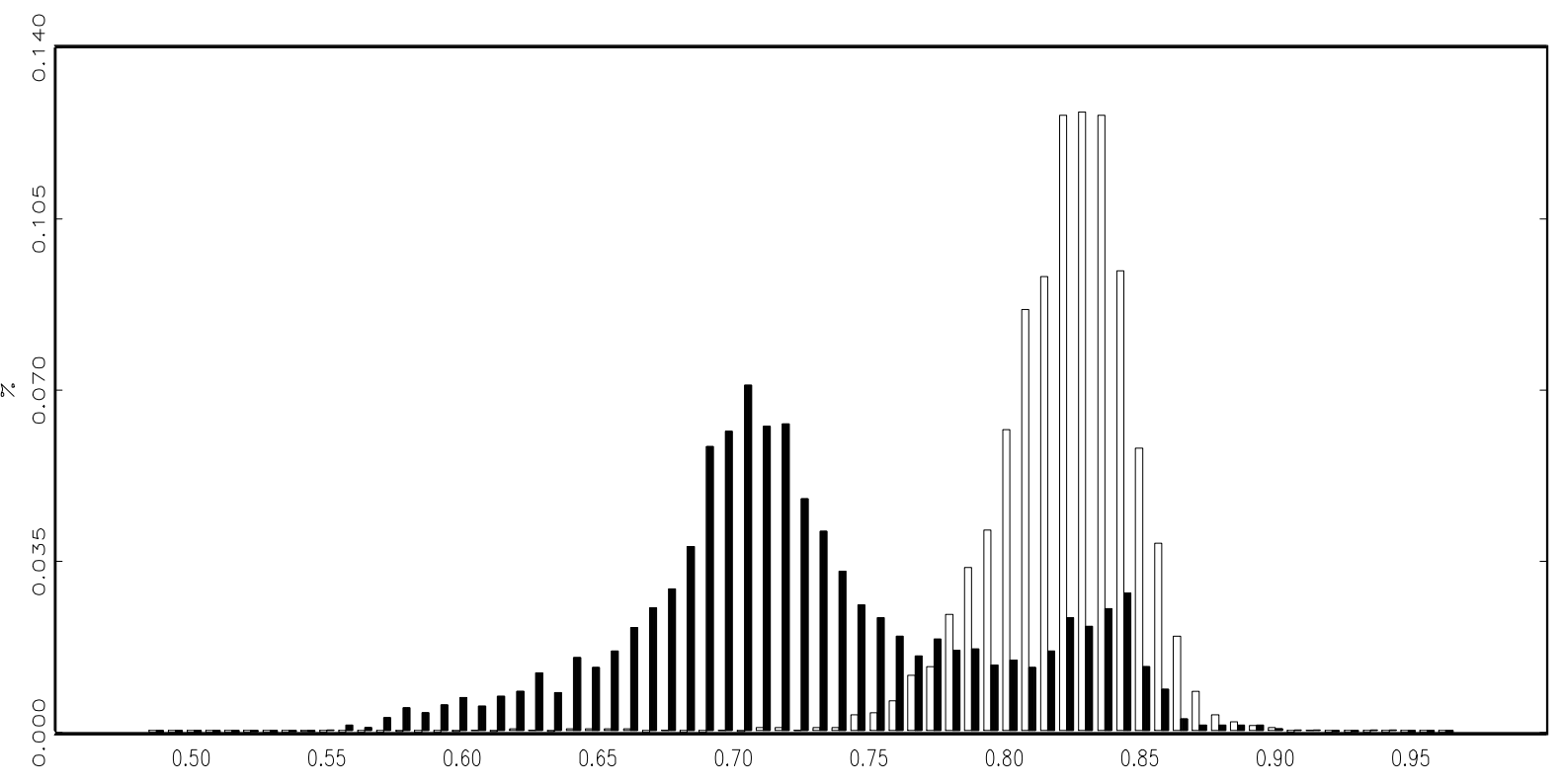

Panel b) Unleaded petrol

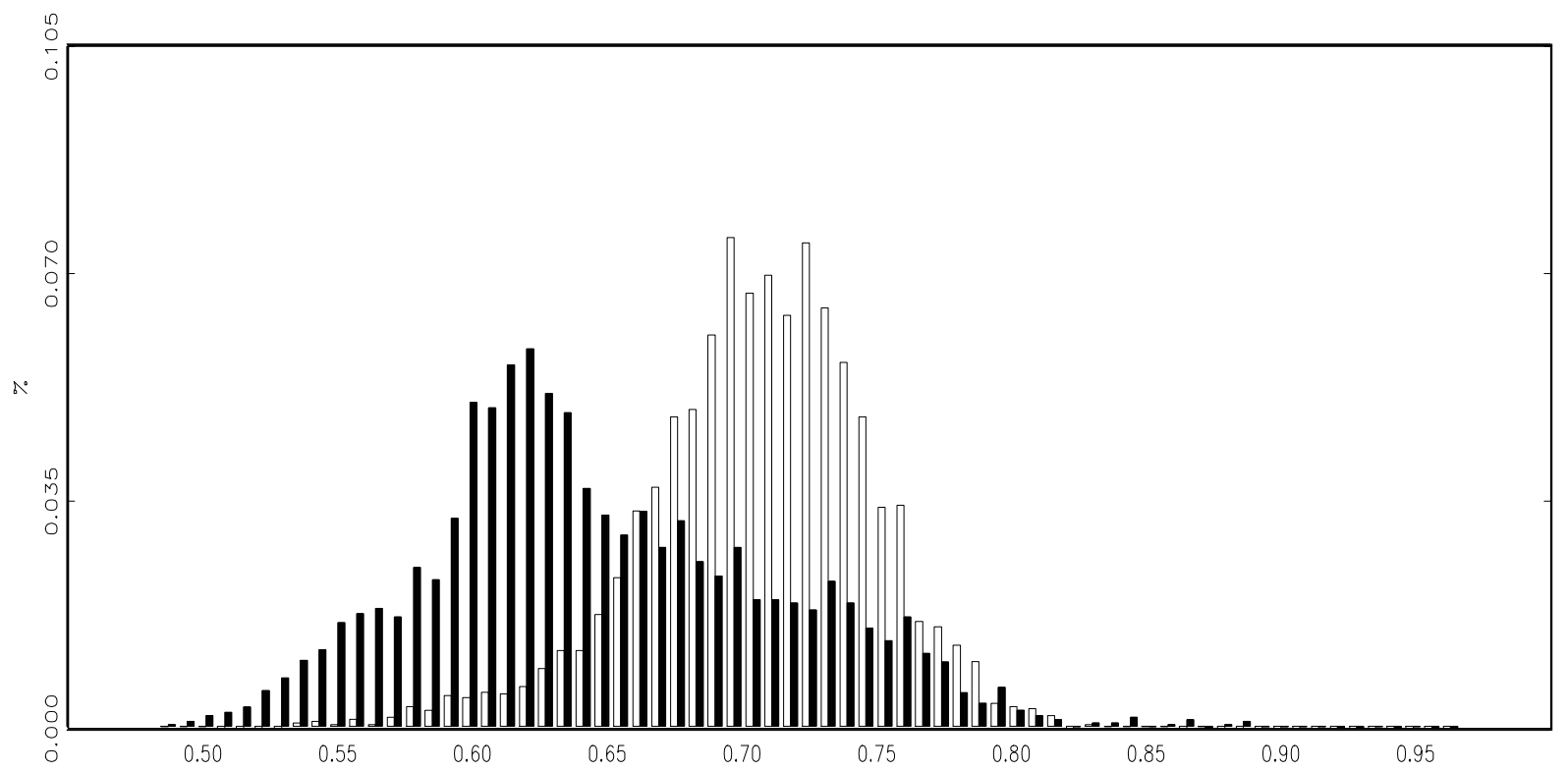

Note: Each observation is a value of $\beta$ estimated for an individual gas station. White bars are for prices in supermarkets and black bars for prices in other gas stations. 
Figure 5: Simulated and actual distributions of price changes (Calvo model versus actual data)

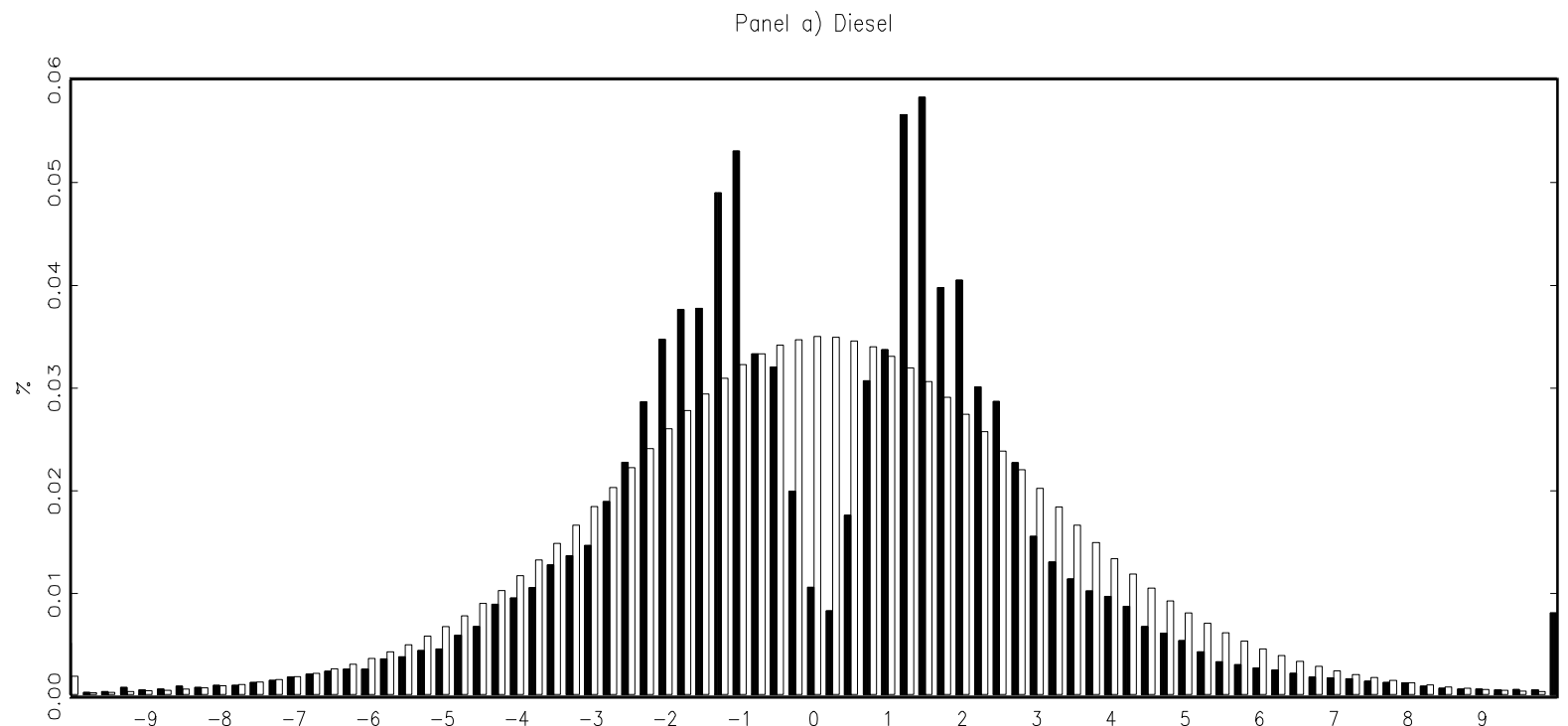

Panel b) Unleaded petrol

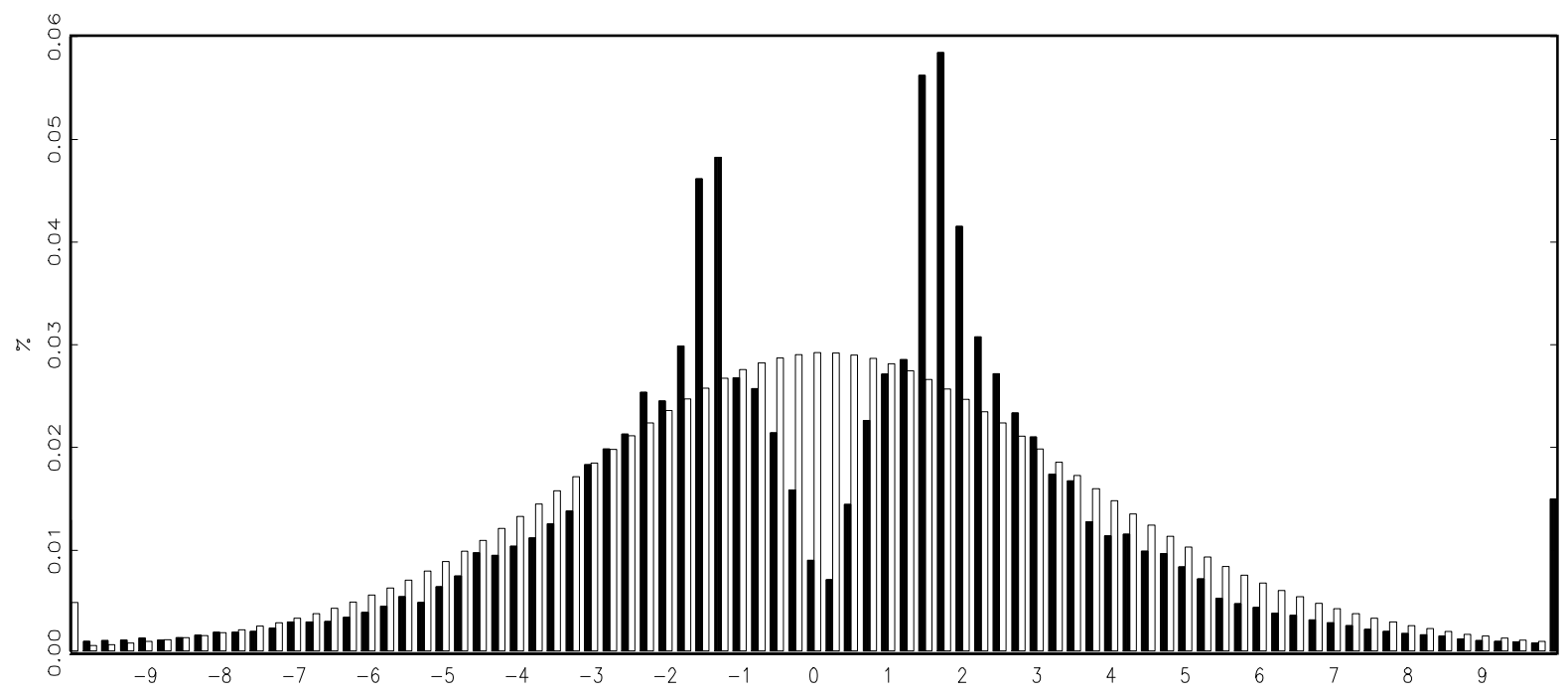

Note: White bars are for the distribution of simulated price changes using the Calvo model and black bars are for the actual distribution of price changes observed in the data. 
Figure 6: Simulated versus actual distribution of price changes (time-varying (S,s) model versus actual data)

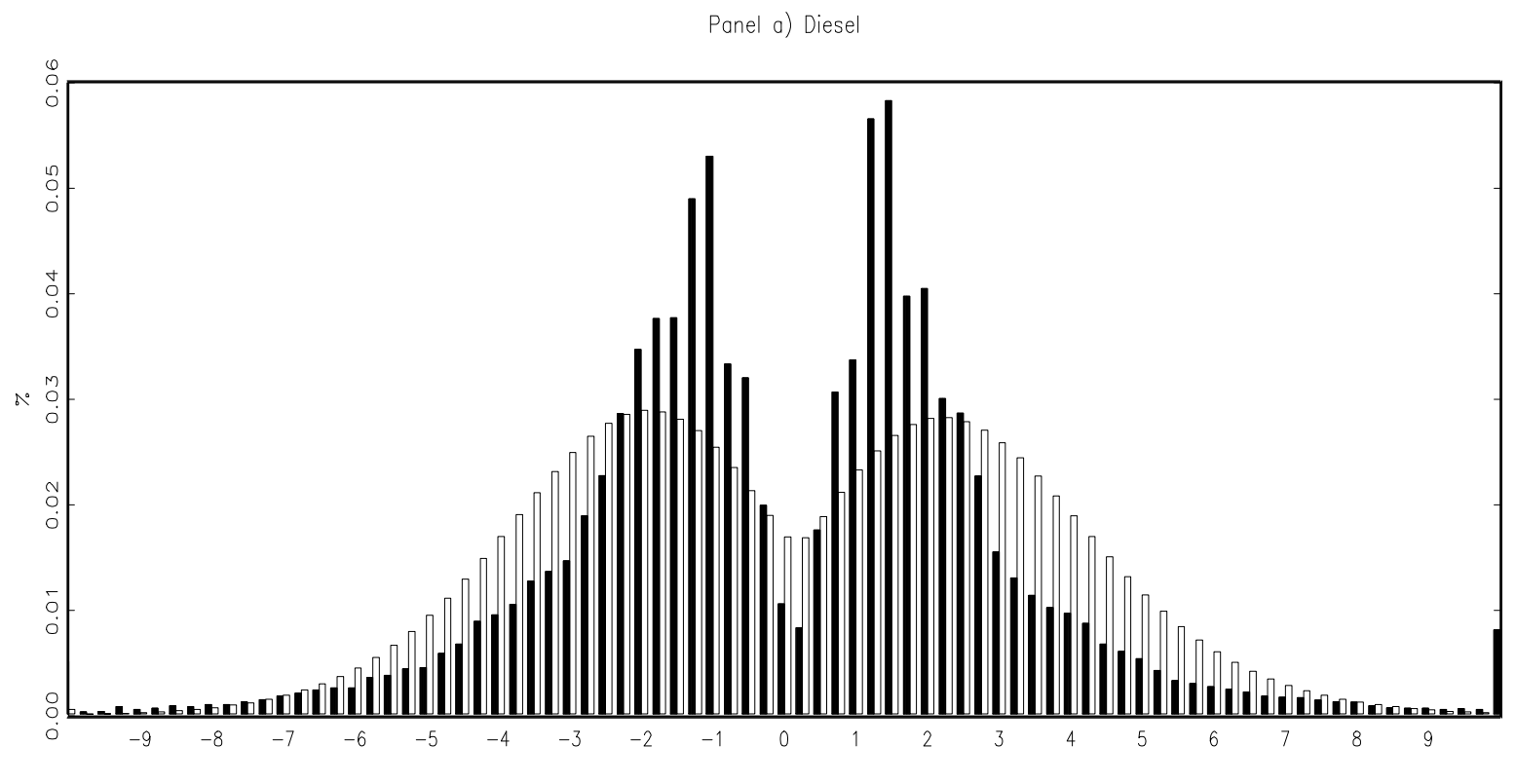

Panel b) Unleaded petrol

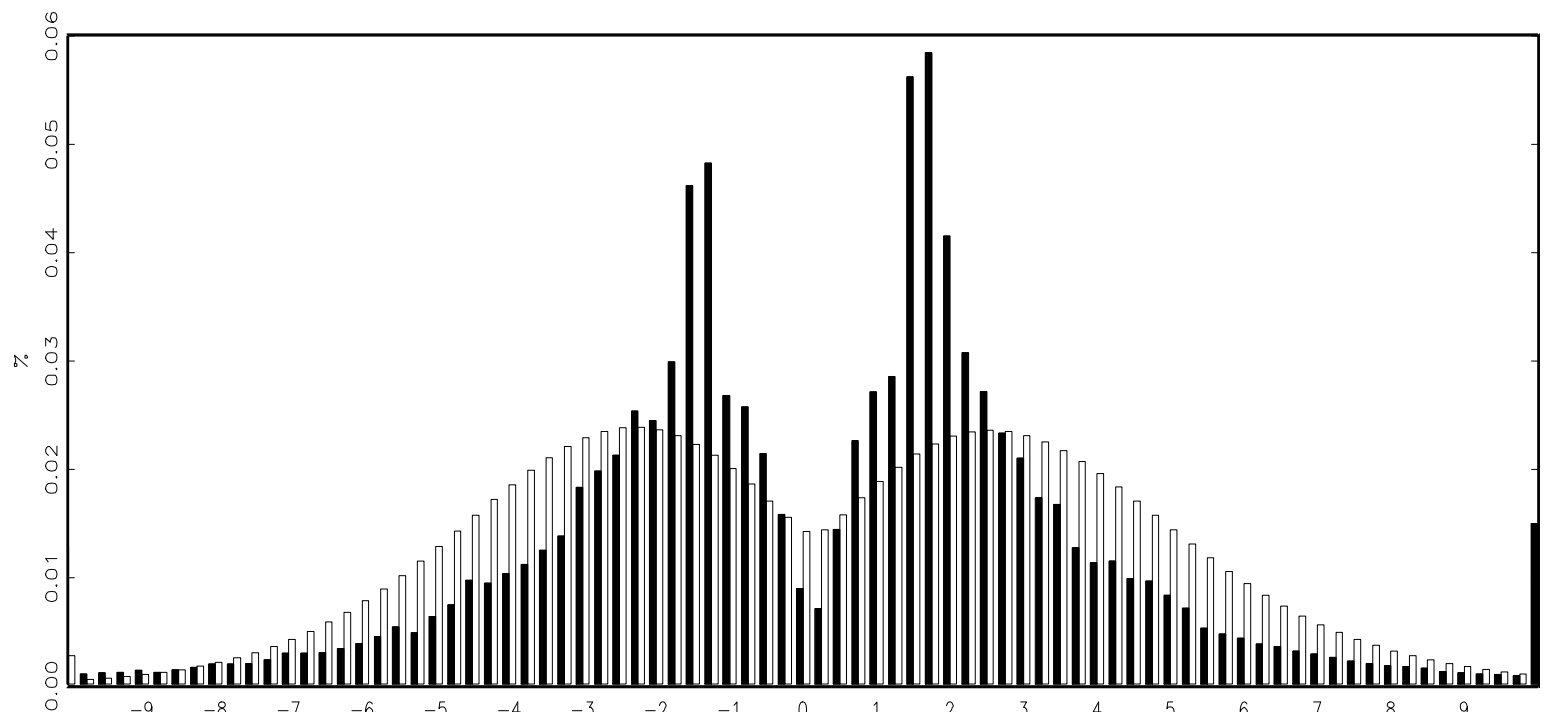

Note: White bars are for the distribution of simulated price changes using the time-varying threshold model and black bars are for the actual distribution of price changes observed in the data. 
Figure 7: Aggregate responses of gasoline inflation to a 1\%-shock on Rotterdam price for the fixed $(\mathrm{S}, \mathrm{s})$ model, Calvo model and time-varying $(\mathrm{S}, \mathrm{s})$ model

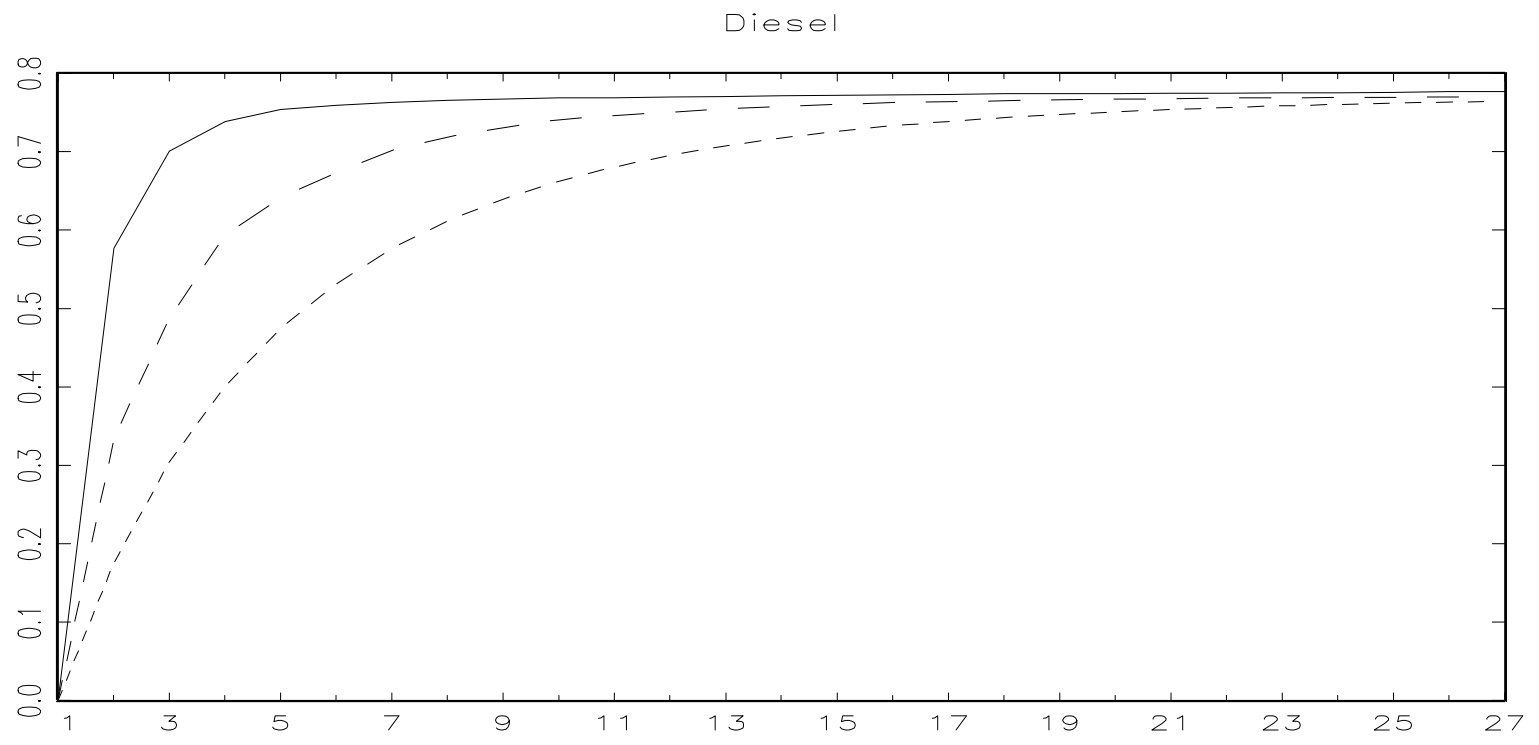

Unleaded petrol

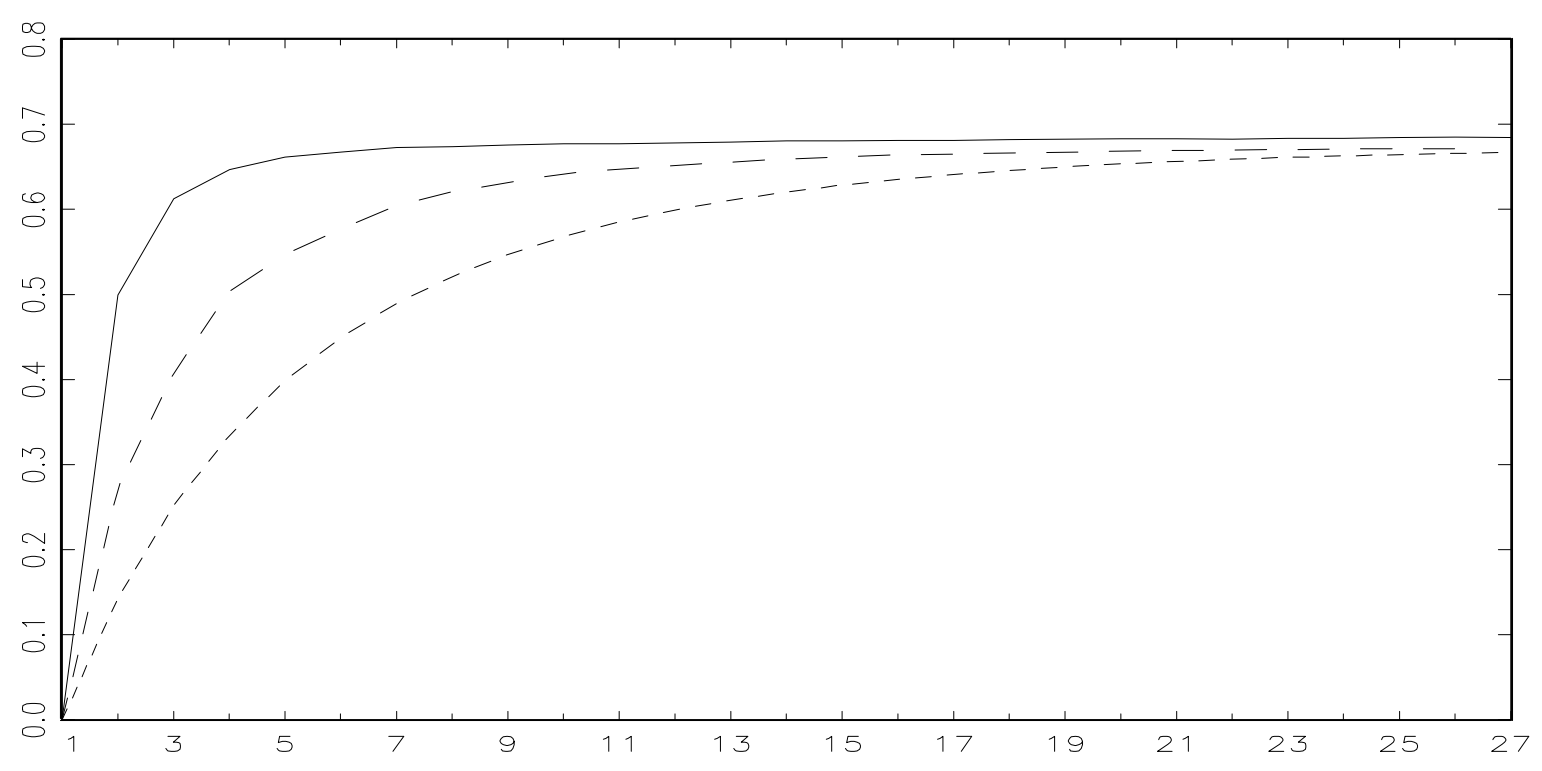

Note: dashed line for the time-varying $(\mathrm{S}, \mathrm{s})$ model, short dashed line for the Calvo model, solid line for the fixed adjustment cost model. 
Figure 8: Aggregate responses of the frequency of price changes to a 1\%-shock on Rotterdam price the fixed (S,s) model, Calvo model and time-varying (S,s) model
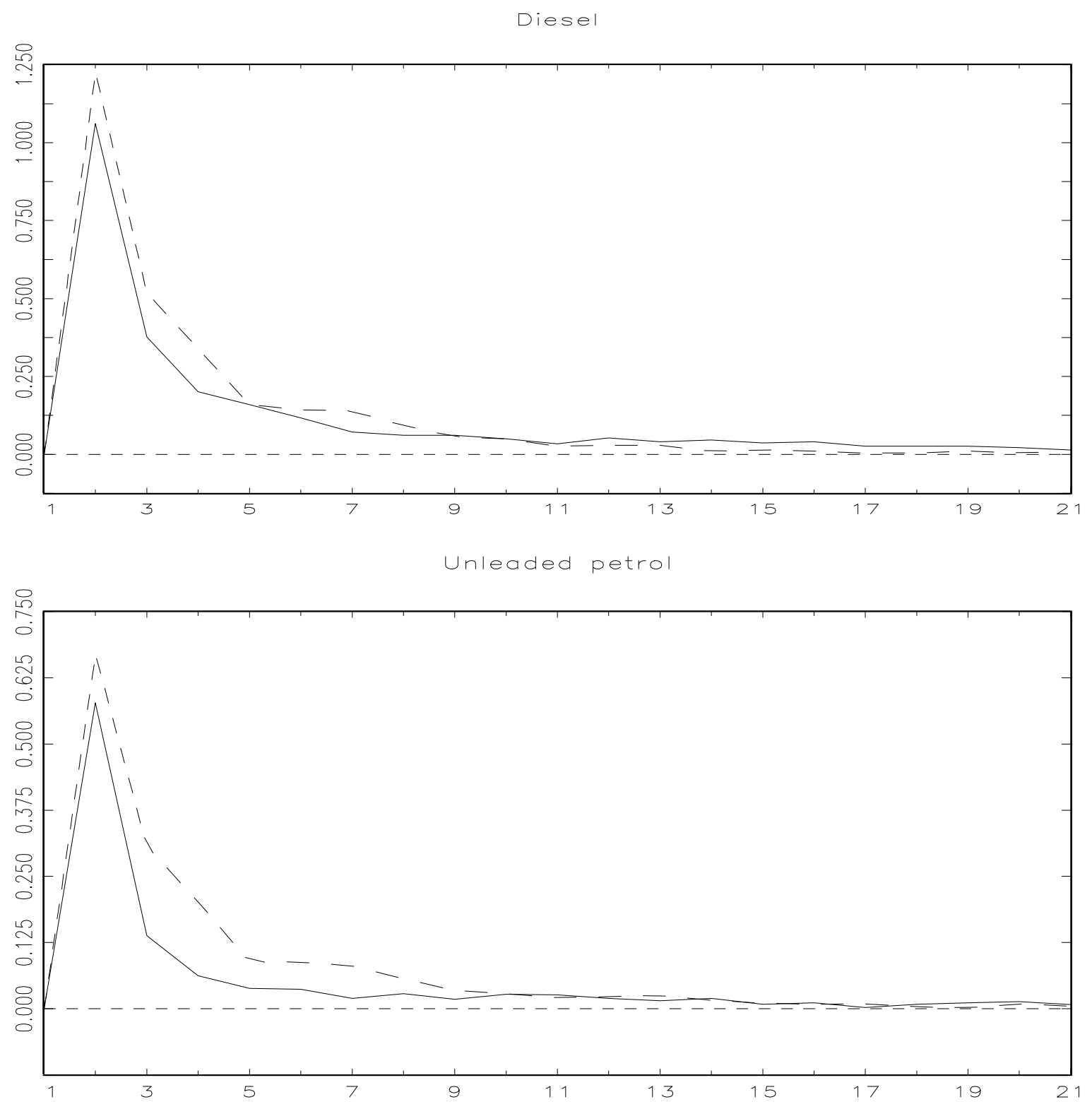

Note: dashed line for the variable adjustment cost model, short dashed line for the Calvo model, solid line for the fixed adjustment cost model. 
Figure 9: Aggregate response of gasoline inflation to shocks on Rotterdam price (time-varying $(\mathrm{S}, \mathrm{s})$ model)

Diesel
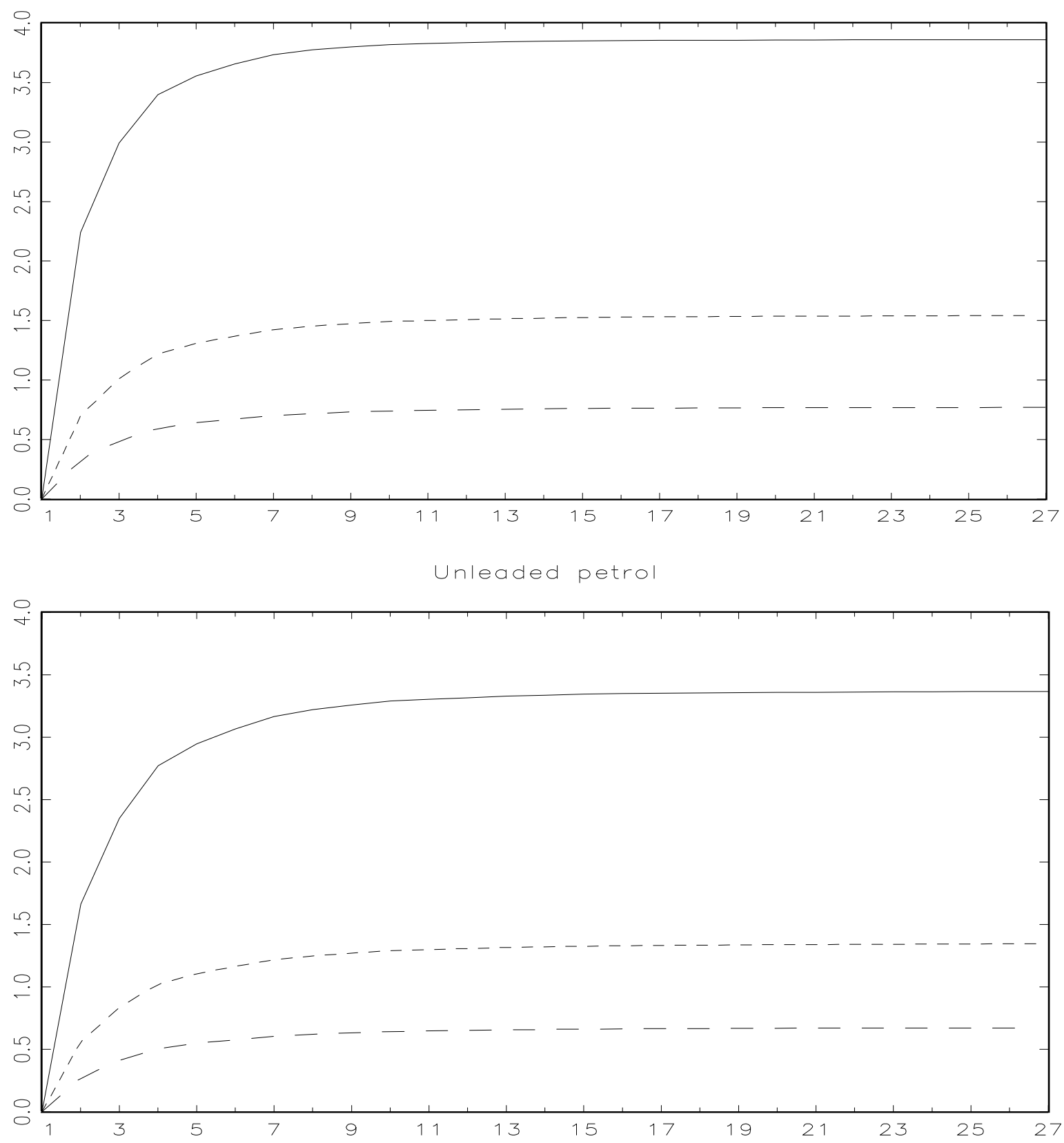

Note: dashed line for the response to a $1 \%$ shock, short dashed line for the response to a $2 \%$ shock, solid line for the response to a $5 \%$ shock. 
Figure 10: Aggregate response of the frequency of price changes to shocks on Rotterdam price (time-varying $(\mathrm{S}, \mathrm{s})$ model)

Diesel

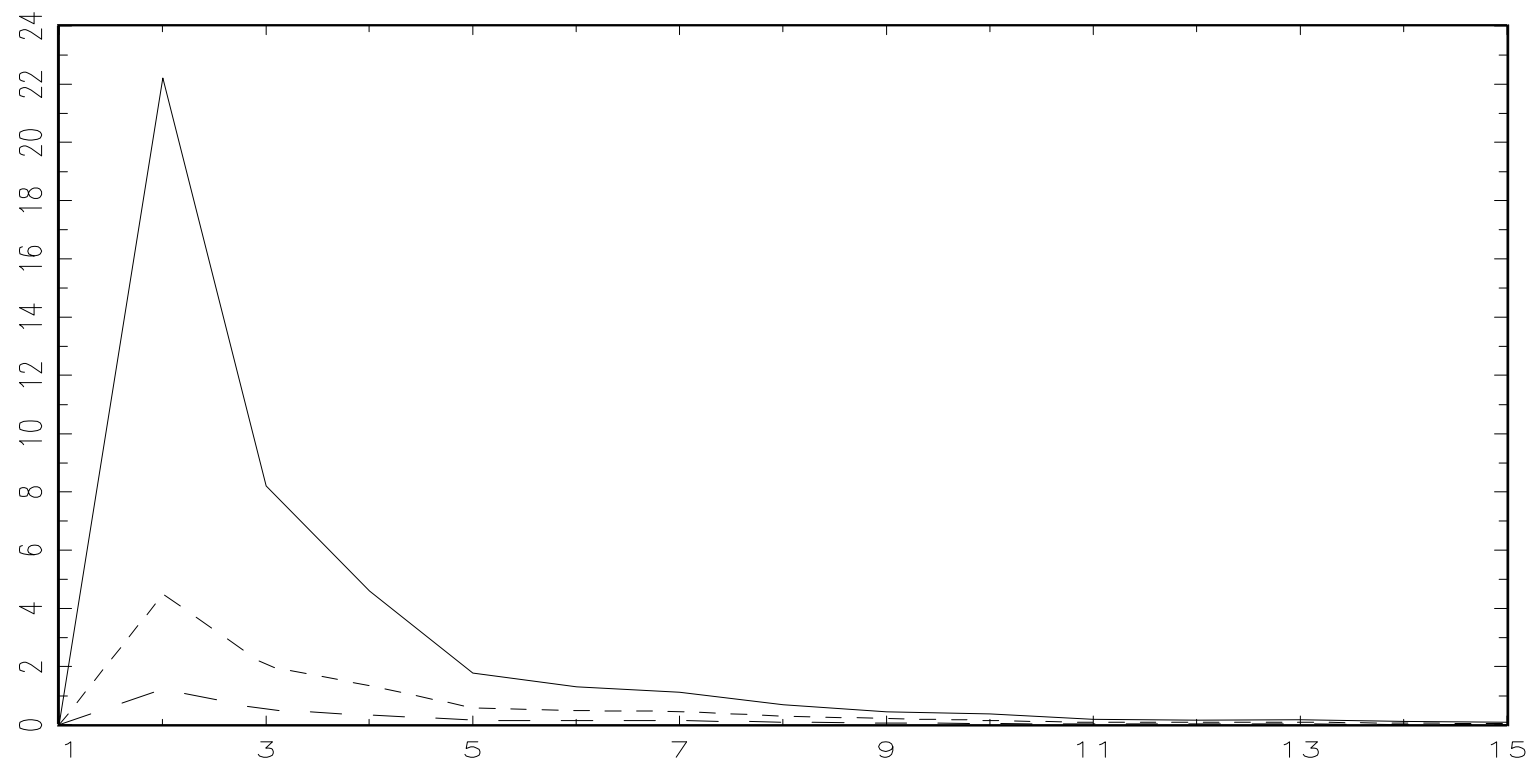

Unleaded petrol

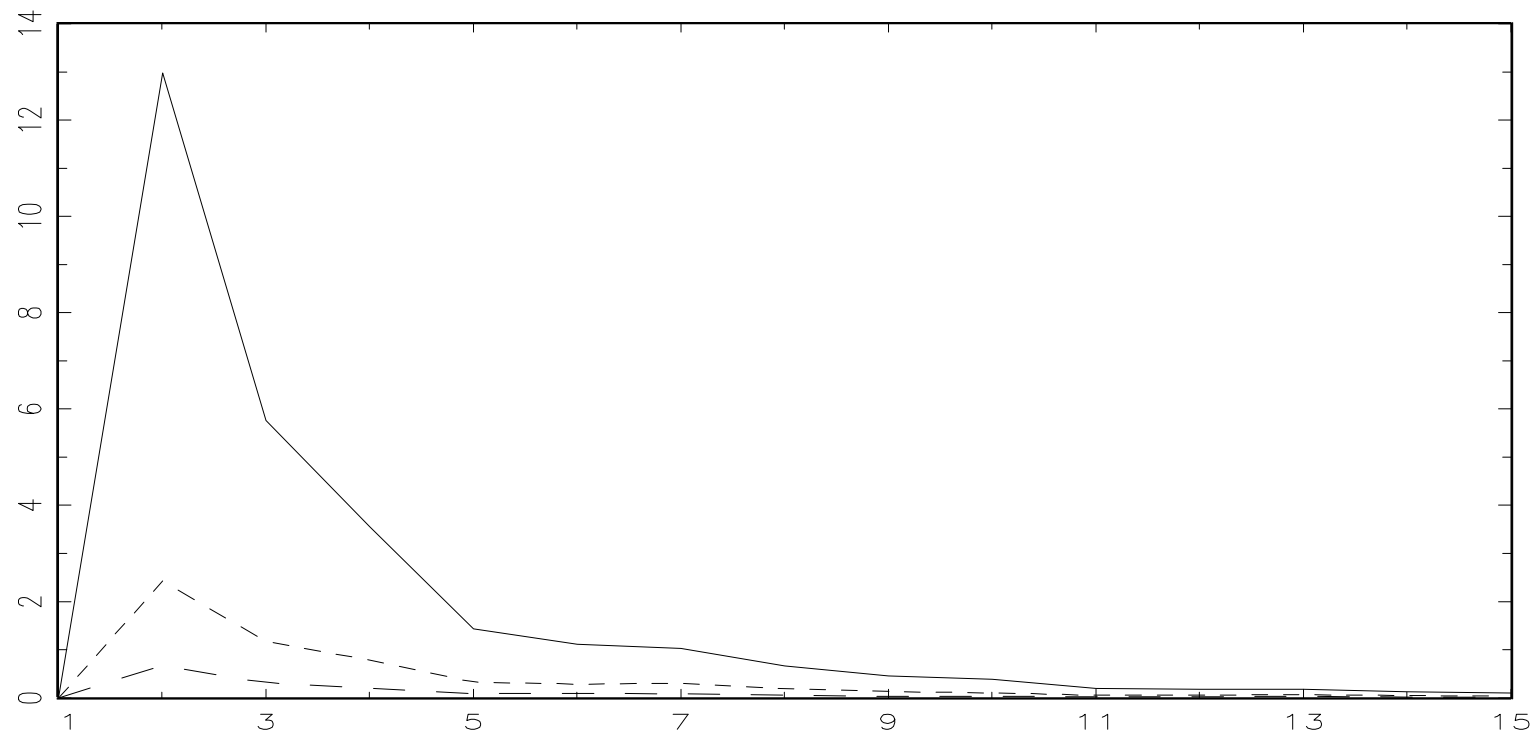

Note: dashed line for the response to a $1 \%$ shock, short dashed line for the response to a $2 \%$ shock, solid line for the response to a $5 \%$ shock. 


\section{APPENDIX}

\section{Likelihood function}

The contribution to the likelihood function of price constancy in firm $i$ at date $t$ is :

$$
\begin{aligned}
& l_{1 i, t}=\operatorname{Pr}\left(d p_{i, t, \tau}=0 \mid p_{i, t-\tau}, X_{i t}, p_{t}^{o}\right) \\
&=\operatorname{Pr}\left(s_{i t}<p_{i, t-\tau}-p_{i, t}^{*}<S_{i t}\right) \\
&=\operatorname{Pr}\left(\gamma_{i s} X_{i t}+\varepsilon_{2, i t}<p_{i, t-\tau}-\alpha_{i}-\beta_{i} p_{t}^{o}-\varepsilon_{1, i t}<\gamma_{i S} X_{i t}-\varepsilon_{2, i t}\right) \\
&=\operatorname{Pr}\left(\varepsilon_{1, i t}+\varepsilon_{2, i t}<p_{i, t-\tau}-\alpha_{i}-\beta_{i} p_{t}^{o}-\gamma_{i s} X_{i t} ; p_{i, t-\tau}-\alpha_{i}-\beta_{i} p_{t}^{o}-\gamma_{i S} X_{i t}<\varepsilon_{1, i t}-\varepsilon_{2, i t}\right) \\
&=\Phi\left[\frac{p_{i, t-\tau}-\alpha_{i}-\beta_{i} p_{t}^{o}-\gamma_{i s} X_{i t}}{\sqrt{\sigma_{1 i}^{2}+\sigma_{2 i}^{2}}}\right] \\
&-\Phi_{2}\left[\frac{p_{i, t-\tau}-\alpha_{i}-\beta_{i} p_{t}^{o}-\gamma_{i s} X_{i t}}{\sqrt{\sigma_{1 i}^{2}+\sigma_{2 i}^{2}}} ; \frac{p_{i, t-\tau}-\alpha_{i}-\beta_{i} p_{t}^{o}-\gamma_{i S} X_{i t}}{\sqrt{\sigma_{1 i}^{2}+\sigma_{2 i}^{2}}} ; \frac{\sigma_{1 i}^{2}-\sigma_{2 i}^{2}}{\sigma_{1 i}^{2}+\sigma_{2 i}^{2}}\right]
\end{aligned}
$$

where $\Phi$ is the c.d.f of the Gaussian distribution and $\Phi_{2}$ is the bivariate c.d.f of the Gaussian distribution.

The contribution to the likelihood function of a price increase in firm $i$ at date $t$ is:

$$
\begin{aligned}
l_{2 i, t} & =\operatorname{Pr}\left(d p_{i, t, \tau}>0 \mid p_{i, t-\tau}, X_{i t}, p_{t}^{o}\right) \\
& =\operatorname{Pr}\left(\varepsilon_{1, i t}=p_{i, t}-\alpha_{i}-\beta_{i} p_{t}^{0}\right) \times \operatorname{Pr}\left[p_{i, t-\tau}-p_{i, t}^{*} \leq s_{i t}, \quad p_{i, t-\tau}-p_{i, t}^{*}<S_{i t} \mid \varepsilon_{1, i t}=p_{i, t}-\alpha_{i}-\beta_{i} p_{t}^{0}\right] \\
& =\frac{1}{\sigma_{1 i}} \phi\left(\frac{p_{i, t-\tau}-\alpha_{i}-\beta_{i} p_{t}^{o}}{\sigma_{1 i}}\right) \\
& \times \operatorname{Pr}\left[\begin{array}{l}
\left.p_{i, t-\tau}-\alpha_{i}-\beta_{i} p_{t}^{0}-\varepsilon_{1, i t} \leq \gamma_{i s} X_{i t}+\varepsilon_{2, i t}, \quad p_{i, t-\tau}-\alpha_{i}-\beta_{i} p_{t}^{0}-\varepsilon_{1, i t}<\gamma_{i S} X_{i t}-\varepsilon_{2, i t}\right] \\
\mid \varepsilon_{1, i t}=p_{i, t}-\alpha_{i}-\beta_{i} p_{t}^{0}
\end{array}\right] \\
& =\frac{1}{\sigma_{1 i}} \phi\left(\frac{p_{i, t-\tau}-\alpha_{i}-\beta_{i} p_{t}^{o}}{\sigma_{1 i}}\right) \times \operatorname{Pr}\left[-d p_{i, t, \tau}-\gamma_{i s} X_{i t} \leq \varepsilon_{2, i t}, \quad d p_{i, t, \tau}+\gamma_{i S} X_{i t}>\varepsilon_{2, i t}\right] \\
& =\frac{1}{\sigma_{1 i}} \phi\left(\frac{p_{i, t-\tau}-\alpha_{i}-\beta_{i} p_{t}^{o}}{\sigma_{1 i}}\right) \times\left[\Phi\left(\frac{d p_{i, t, \tau}+\gamma_{i S} X_{i t}}{\sigma_{2 i}}\right)-\Phi\left(\frac{-d p_{i, t, \tau}-\gamma_{i s} X_{i t}}{\sigma_{2 i}}\right)\right]
\end{aligned}
$$

where $\phi$ is the p.d.f of the Gaussian distribution and $d p_{i, t, \tau}=p_{i t}-p_{i t-\tau}$. 
The contribution to the likelihood function of a price decrease in firm $i$ at date $t$ is:

$$
\begin{aligned}
l_{3 i, t} & =\operatorname{Pr}\left(d p_{i, t, \tau}<0 \mid p_{i, t-\tau}, X_{i t}, p_{t}^{o}\right) \\
& =\operatorname{Pr}\left(\varepsilon_{1, i t}=p_{i, t}-\alpha_{i}-\beta_{i} p_{t}^{0}\right) \times \operatorname{Pr}\left[p_{i, t-\tau}-p_{i, t}^{*}>s_{i t}, \quad p_{i, t-\tau}-p_{i, t}^{*} \geq S_{i t} \mid \varepsilon_{1, i t}=p_{i, t}-\alpha_{i}-\beta_{i} p_{t}^{0}\right] \\
& =\frac{1}{\sigma_{1 i}} \phi\left(\frac{p_{i, t-\tau}-\alpha_{i}-\beta_{i} p_{t}^{o}}{\sigma_{1 i}}\right) \\
& \times \operatorname{Pr}\left[\begin{array}{c}
\left.p_{i, t-\tau}-\alpha_{i}-\beta_{i} p_{t}^{0}-\varepsilon_{1, i t}>\gamma_{i s} X_{i t}+\varepsilon_{2, i t}, \quad p_{i, t-\tau}-\alpha_{i}-\beta_{i} p_{t}^{0}-\varepsilon_{1, i t} \geq \gamma_{i S} X_{i t}-\varepsilon_{2, i t}\right] \\
\mid \varepsilon_{1, i t}=p_{i, t}-\alpha_{i}-\beta_{i} p_{t}^{0}
\end{array}\right] \\
& =\frac{1}{\sigma_{1 i}} \phi\left(\frac{p_{i, t-\tau}-\alpha_{i}-\beta_{i} p_{t}^{o}}{\sigma_{1 i}}\right) \times \operatorname{Pr}\left[-d p_{i, t, \tau}-\gamma_{i s} X_{i t}>\varepsilon_{2, i t}, \quad d p_{i, t, \tau}+\gamma_{i S} X_{i t}<\varepsilon_{2, i t}\right] \\
& =\frac{1}{\sigma_{1 i}} \phi\left(\frac{p_{i, t-\tau}-\alpha_{i}-\beta_{i} p_{t}^{o}}{\sigma_{1 i}}\right) \times\left[\Phi\left(\frac{-d p_{i, t, \tau}-\gamma_{i s} X_{i t}}{\sigma_{2 i}}\right)-\Phi\left(\frac{d p_{i, t, \tau}+\gamma_{i S} X_{i t}}{\sigma_{2 i}}\right)\right]
\end{aligned}
$$

where $\phi$ is the p.d.f of the Gaussian distribution and $d p_{i, t, \tau}=p_{i t}-p_{i t-\tau}$.

The likelihood function for an i.i.d. sample of a given firm $i$ is thus:

$$
\ln L_{i}(\theta)=\sum_{t=1}^{T_{i}}\left(l_{1 i, t} \times y_{1 i t}+l_{2 i, t} \times y_{2 i t}+l_{3 i, t} \times y_{3 i t}\right)
$$

where $y_{1 i t}=1$ if $d p_{i, t, \tau}=0$ and 0 otherwise, $y_{2 i t}=1$ if $d p_{i, t, \tau}<0$ and 0 otherwise and $y_{3 i t}=1$ if $d p_{i, t, \tau}>0$ and 0 otherwise. 
Figure A: Average retail prices (individual data set), weekly retail prices published by the Ministry of Economy and wholesale market prices (Rotterdam)

a) diesel

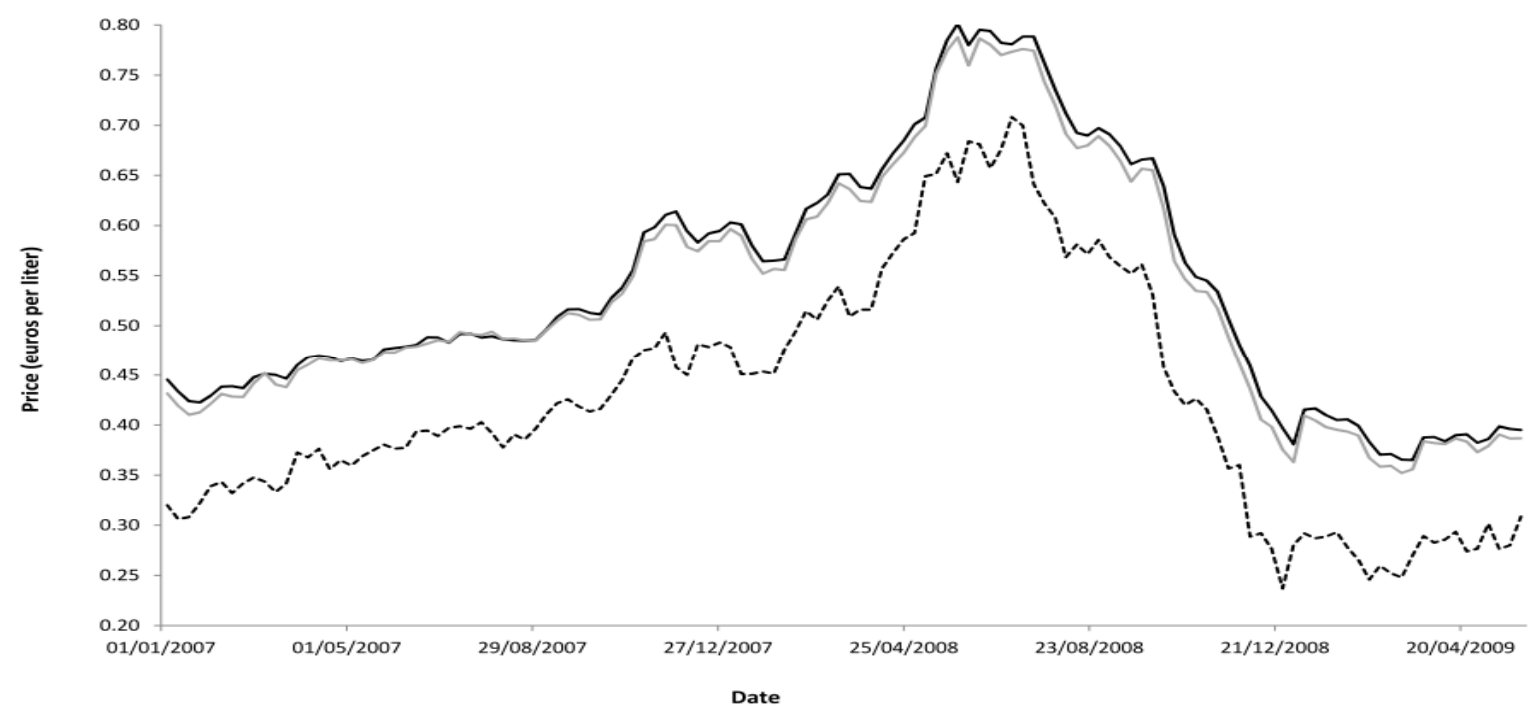

a) unleaded petrol

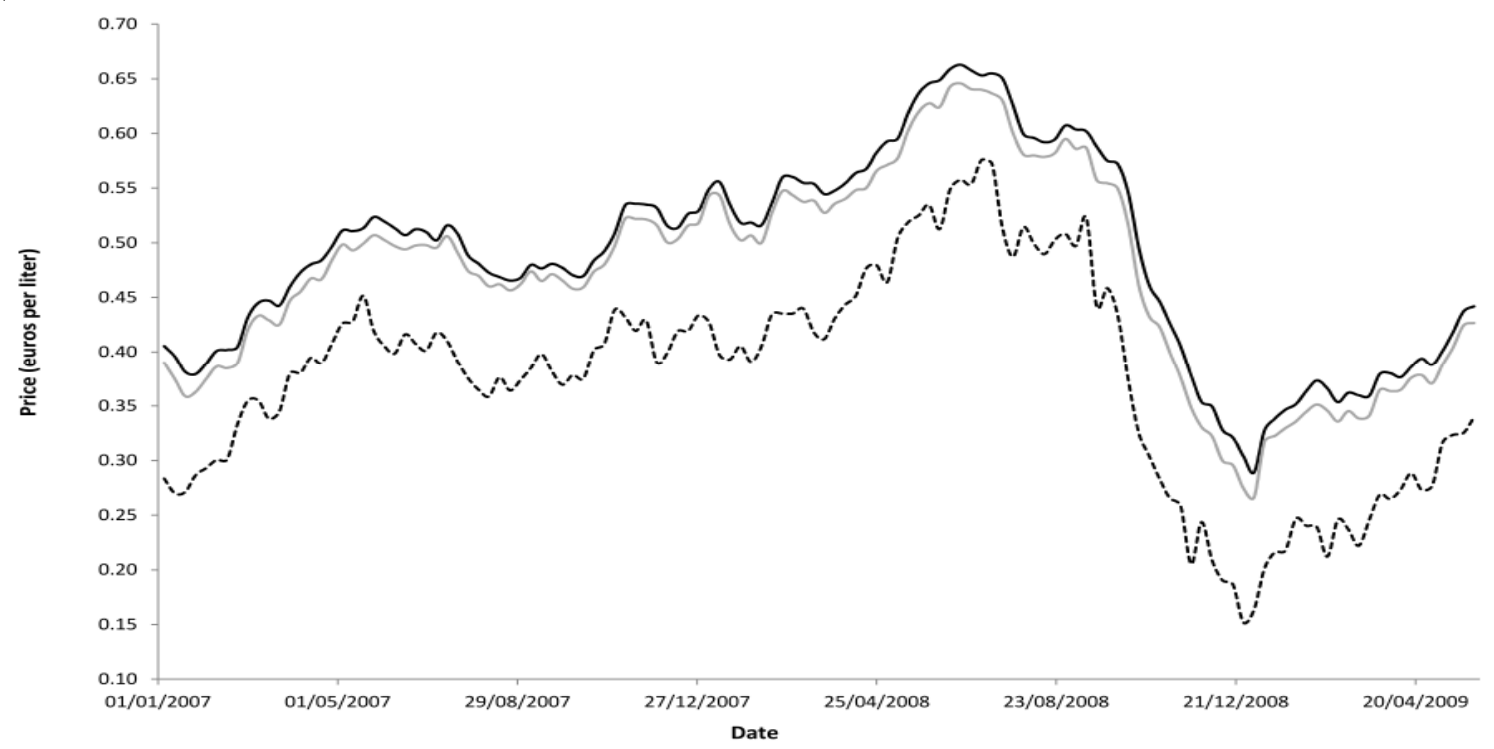

Note: dashed line is for Rotterdam prices, black line is for the average of individual prices collected in our data set and grey line is for the aggregate retail price series published by the Ministry of Economy each Friday. 


\section{Figure B: Adjustment hazard functions}

a) Diesel

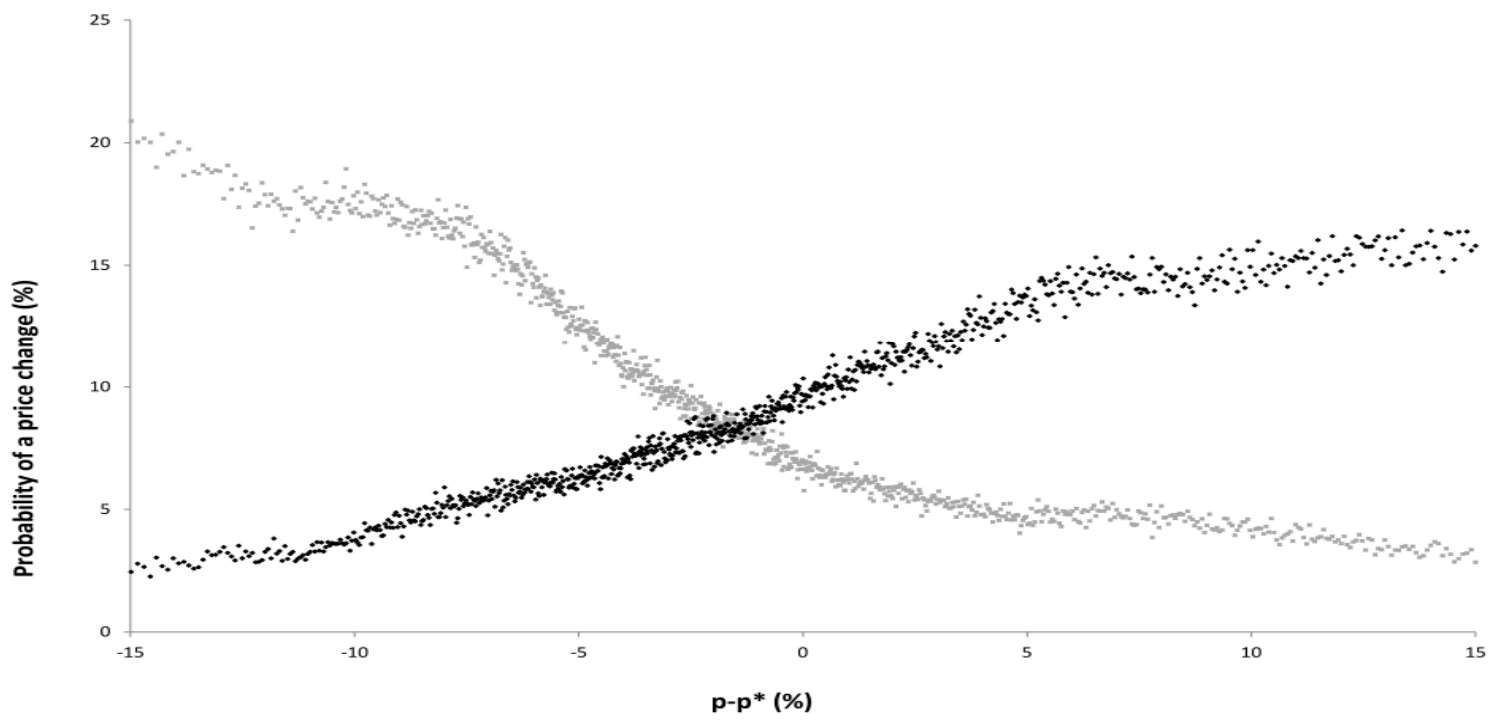

b) Unleaded petrol

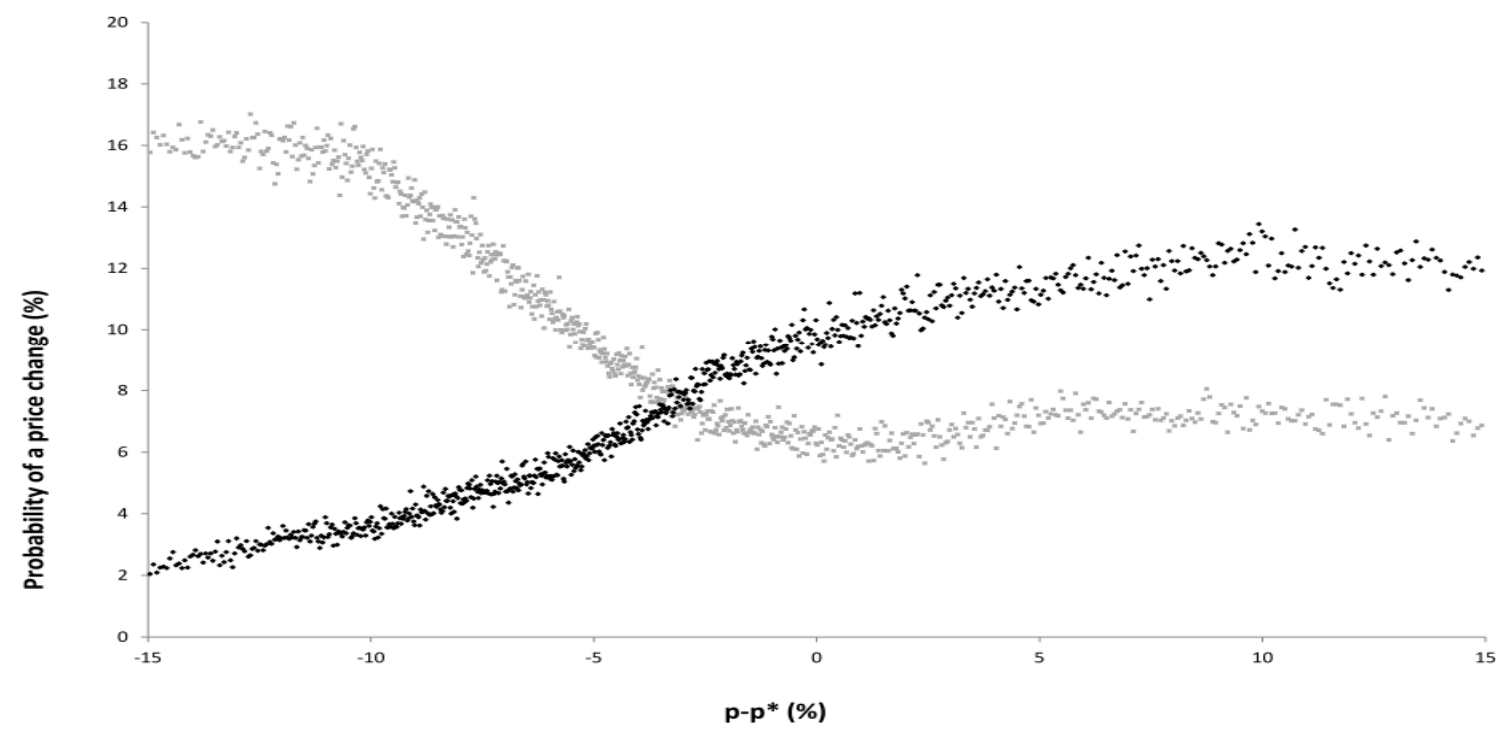

Note. Adjustment hazard functions are computed as the probability of price increases or decreases as a function of the log difference between the observed nominal price and the frictionless price (the number of classes of $p-p *$ is 1,000$)$. For each retailer, the difference $p-p *$ is centered. $p$ is the log price of fuel in our microdata set. $p *$ is the log Rotterdam market price. Black points are for probability of price decreases. Grey points are for probability of price increases. 
Table A: Distribution of Price Changes and Average Duration by the Last Digit of Price

\begin{tabular}{rrrrr}
\hline \hline & \multicolumn{2}{c}{ Diesel } & \multicolumn{2}{c}{ Unleaded Petrol } \\
& \% of price & \multicolumn{1}{c}{ Average price } & \% of price & Average price \\
& trajectories & duration (in days) & trajectories & duration (in days) \\
\hline 0 & 29.0 & 6.7 & 29.5 & 7.0 \\
1 & 2.9 & 4.2 & 3.0 & 4.6 \\
2 & 4.2 & 4.1 & 4.2 & 4.4 \\
3 & 3.6 & 4.3 & 3.6 & 4.7 \\
4 & 7.2 & 4.2 & 7.3 & 4.4 \\
5 & 8.8 & 4.5 & 8.8 & 4.9 \\
6 & 3.7 & 4.4 & 3.8 & 4.7 \\
7 & 4.1 & 4.4 & 3.9 & 4.7 \\
8 & 4.7 & 4.7 & 4.6 & 5.0 \\
9 & 31.8 & 4.9 & 31.4 & 5.3 \\
\hline
\end{tabular}

Note: We consider prices including all taxes, the proportion of price trajectories is computed as the ratio of number of price trajectories ending with one figure on all price trajectories and we compute the simple average duration. The last digit is the third one. 
Table B: Estimation results - Fixed adjustment cost model

\begin{tabular}{c|rccccccccc}
\hline \hline \multicolumn{1}{c}{ Diesel } & \multicolumn{4}{c}{ Unleaded petrol } \\
\multicolumn{1}{c}{} & Q25 & Q50 & Q75 & Mean & Stdc & Q25 & Q50 & Q75 & Mean & Stdc \\
\hline$\alpha$ & 1.56 & 2.39 & 3.68 & 2.62 & 1.39 & -2.59 & -1.51 & -0.27 & -1.34 & 1.91 \\
$\beta$ & 0.72 & 0.80 & 0.84 & 0.78 & 0.07 & 0.64 & 0.69 & 0.73 & 0.69 & 0.06 \\
$\sigma_{1}$ & 2.31 & 2.63 & 3.04 & 2.72 & 0.63 & 2.80 & 3.25 & 3.80 & 3.38 & 0.86 \\
$\gamma_{S}$ & 3.22 & 4.02 & 5.17 & 4.31 & 1.65 & 4.13 & 5.21 & 6.68 & 5.56 & 2.03 \\
$\gamma_{s}$ & -5.21 & -4.16 & -3.39 & -4.38 & 1.56 & -6.39 & -5.08 & -4.11 & -5.39 & 1.86 \\
\hline \hline
\end{tabular}

Note: We estimate for each individual gas station a fixed (S,s) model and then compute statistics on the parameter estimates we obtained. Observations on Sundays are excluded from the sample used for the estimation.

Table C: Estimation results - Calvo model

\begin{tabular}{c|rrrrrrrrrr}
\hline \hline \multicolumn{1}{c}{ Diesel } & \multicolumn{5}{c}{ Unleaded petrol } \\
& Q25 & Q50 & Q75 & Mean & Stdc & Q25 & Q50 & Q75 & Mean & Stdc \\
\hline$\alpha$ & 1.21 & 1.96 & 3.15 & 2.19 & 1.31 & -3.19 & -2.19 & -1.11 & -2.11 & 1.75 \\
$\beta$ & 0.71 & 0.80 & 0.83 & 0.77 & 0.07 & 0.63 & 0.68 & 0.72 & 0.68 & 0.07 \\
$\sigma_{1}$ & 1.63 & 1.78 & 1.98 & 1.83 & 0.32 & 1.93 & 2.16 & 2.43 & 2.22 & 0.46 \\
$\lambda_{1}$ & -1.40 & -1.27 & -1.11 & -1.25 & 0.27 & -1.48 & -1.35 & -1.19 & -1.32 & 0.29 \\
$\lambda_{2}$ & 1.11 & 1.27 & 1.40 & 1.25 & 0.25 & 1.13 & 1.27 & 1.40 & 1.26 & 0.26 \\
\hline \hline
\end{tabular}

Note: We estimate for each individual gas station a "Calvo" model and then compute statistics on the parameter estimates we obtained. $\lambda_{1}$ (resp. $\lambda_{2}$ ) is the intercept trigerring randomly price increases (resp. decreases). Observations on Sundays are excluded from the sample used for the estimation. 

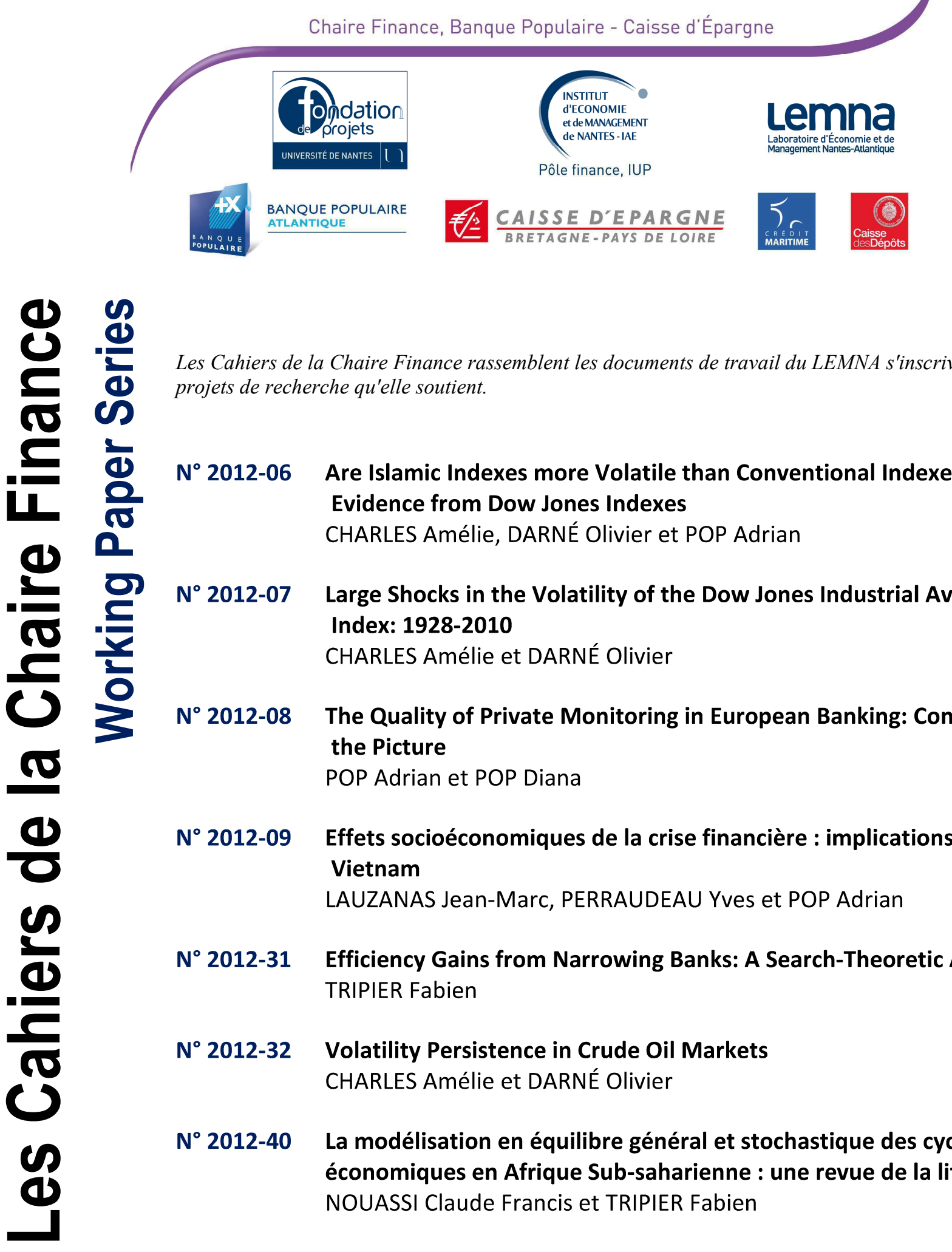

Les Cahiers de la Chaire Finance rassemblent les documents de travail du LEMNA s'inscrivant dans des projets de recherche qu'elle soutient.
$\mathrm{N}^{\circ}$ 2012-06 Are Islamic Indexes more Volatile than Conventional Indexes? Evidence from Dow Jones Indexes
CHARLES Amélie, DARNÉ Olivier et POP Adrian
$N^{\circ}$ 2012-07 Large Shocks in the Volatility of the Dow Jones Industrial Average Index: 1928-2010
CHARLES Amélie et DARNÉ Olivier
$\mathbf{N}^{\circ}$ 2012-08 The Quality of Private Monitoring in European Banking: Completing the Picture
POP Adrian et POP Diana
$N^{\circ}$ 2012-09 Effets socioéconomiques de la crise financière : implications pour le Vietnam
LAUZANAS Jean-Marc, PERRAUDEAU Yves et POP Adrian
$N^{\circ}$ 2012-31 Efficiency Gains from Narrowing Banks: A Search-Theoretic Approach TRIPIER Fabien
$\mathbf{N}^{\circ}$ 2012-32 Volatility Persistence in Crude Oil Markets CHARLES Amélie et DARNÉ Olivier

$N^{\circ}$ 2012-40 La modélisation en équilibre général et stochastique des cycles économiques en Afrique Sub-saharienne : une revue de la littérature NOUASSI Claude Francis et TRIPIER Fabien

Les opinions exposées dans ce document n'engagent que les auteurs. Ceux-ci assument la responsabilité de toute erreur ou omission.

La Chaire Finance est une initiative de la Banque Populaire Atlantique, la Caisse d'Epargne Bretagne-Pays de Loire, la Caisse des Dépôts, du Crédit Maritime et de l'Université de Nantes, sous l'égide de la Fondation de Projets de I'Université de Nantes.

Site web : http://www.univ-nantes.fr/fondation/chairefinance 
Chaire Finance, Banque Populaire - Caisse d’Épargne

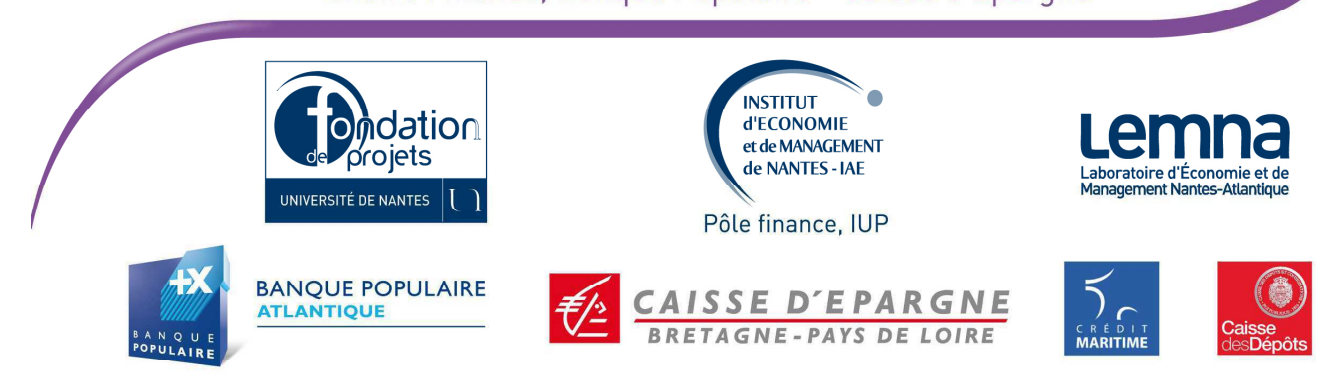
(3) $\mathrm{N}^{\circ}$ 2012-41 The dynamics of gasoline prices : Evidence from daily French micro GAUTIER Erwan et LE SAOUT Ronan

co

()

$\boldsymbol{0}$

$\frac{0}{0}$

$\boldsymbol{\infty}$

()

1 